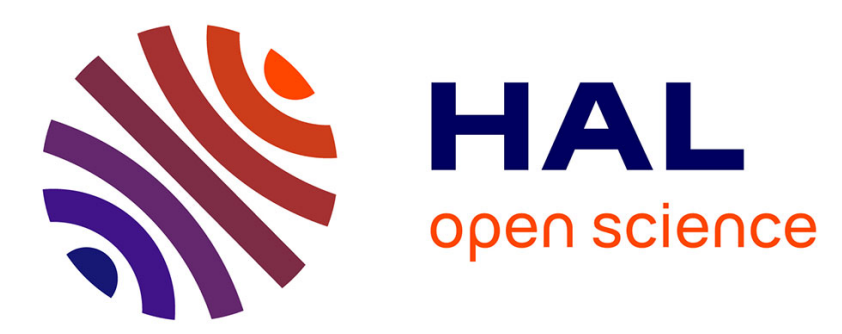

\title{
Modeling contact size effect on fretting wear: a combined contact oxygenation - third body approach
}

Soha Baydoun, Siegfried Fouvry, Sylvie Descartes

\section{To cite this version:}

Soha Baydoun, Siegfried Fouvry, Sylvie Descartes. Modeling contact size effect on fretting wear: a combined contact oxygenation - third body approach. Wear, 2022, 488-489, pp.204168. 10.1016/j.wear.2021.204168 . hal-03453455

\section{HAL Id: hal-03453455 \\ https://hal.science/hal-03453455}

Submitted on 29 Nov 2021

HAL is a multi-disciplinary open access archive for the deposit and dissemination of scientific research documents, whether they are published or not. The documents may come from teaching and research institutions in France or abroad, or from public or private research centers.
L'archive ouverte pluridisciplinaire HAL, est destinée au dépôt et à la diffusion de documents scientifiques de niveau recherche, publiés ou non, émanant des établissements d'enseignement et de recherche français ou étrangers, des laboratoires publics ou privés. 


\title{
Modeling contact size effect on fretting wear: a combined contact oxygenation - third body approach
}

\section{Soha Baydoun ${ }^{\mathrm{a}}$, Siegfried Fouvry ${ }^{\mathrm{a}^{*}}$, Sylvie Descartes ${ }^{\mathrm{b}^{*}}$}

\author{
${ }^{a}$ Ecole Centrale de Lyon, LTDS Laboratory, 36 av Guy de Collongue, 69130 Ecully, France \\ bUniv Lyon, INSA Lyon, CNRS, LaMCoS, UMR5259, 69621 Villeurbanne, France \\ ${ }^{*}$ Corresponding authors
}

E-mail addresses: siegfried.fouvry@ec-lyon.fr (S. Fouvry), sylvie.descartes@insa-lyon.fr (S. Descartes)

Key words: Fretting Wear; Contact size effect; Friction energy wear modeling; Third Body; Contact Oxygenation.

\section{Abstract}

This study investigates the effect of the contact size and the gross-slip sliding amplitude on the fretting wear rate of a steel flat-on-flat interface. Results confirm an asymptotic decrease of the wear rate with the contact size. This evolution is induced by an easier oxygen access to the interface favoring abrasive wear according to the Contact Oxygenation Concept ( $\mathrm{COC}$ ) and by a faster ejection of the protective debris particles from the interface according to the Third Body Theory (TBT). To decouple these COC and TBT contributions, the effect of the sliding amplitude and the contact orientation with respect to the sliding direction is assessed using an original macro-texturation test strategy. Wear rate evolutions as well as SEM-EDX fretting scar analyses suggested that $\mathrm{COC}$ is mainly driven by the minimum distance between the contact center and the open air contact edges $\left(\mathrm{L}_{\mathrm{COC}}\right)$, whereas $\mathrm{TBT}$ wear process is chiefly controlled by the ratio of the collinear contact length to the sliding amplitude $\left(\mathrm{L}_{\mathrm{TBT}} / \delta_{\mathrm{g}}\right)$. Assuming a weighted influence of the contact oxygenation process on the TBT wear process, a simple power-law formulation is introduced to quantify the contact size effect on the 
energy wear rate fluctuation. A very good correlation with the experiments confirms the stability of the proposal.

\section{Introduction}

Fretting is a surface degradation process invariably observed when two bodies in contact experience small amplitude oscillatory movements [1]. Wear and fatigue cracking mechanisms may interact depending on the loading conditions. When larger sliding amplitudes are imposed inducing gross slip condition, wear process caused by debris formation and ejection prevails [2]. Fretting-induced damage is a widespread problem that manifests itself in a wide range of industrial applications ranging from cables and riveted connections in civil engineering contacts to blade/disk assemblies in aeronautics $[3,4]$. Many efforts were made during the past decades to investigate how the contact loading conditions such as the normal force, frequency, sliding amplitude, contact size, ambient and temperature conditions could influence fretting wear [5-12]. Additionally, different strategies were applied to quantify wear rate evolution. Archard [13] wear law is the most common approach expressing the wear volume as a linear function of the product of the normal force by the sliding distance. This law was completed considering the energy wear approach linking the wear volume extension to the friction work dissipated in the interface $[5,14,15]$. Assuming a linear correlation, a friction energy wear coefficient can be extracted. One advantage of this formulation compared to Archard approach is the possibility to take into account the effect of the friction coefficient [16]. For constant friction behaviors, both Archard and friction energy wear approaches lead to similar conclusions although the friction work is intrinsically more pertinent to describe the cyclic shear strains generated at the interface. Another 
strategy to assess fretting wear damage consists in applying the Third Body Theory (TBT) [17-19]. The wear volume extension is expressed here as a balance between the debris formation flow generated at the fretted interfaces (first bodies) and the debris ejection process expelling the so-called "Third Body (TB)" from the interface. This approach provides a more physical description of the fretting wear process but is still not easy to implement in practical situations due to the difficulty of expressing the debris flow parameter. However, by combining both the friction energy and the third body approaches, this paper will underline the benefit of considering these two tribological concepts to better predict fretting wear volume extension.

A key problem in fretting wear analysis is the difficultly to extrapolate the wear rates extracted from small laboratory fretting wear tests to predict the wear volume extension in large industrial interfaces. Like many damage processes as the fatigue of materials, there is a crucial interest to better formalize the contact size effect in the fretting wear. Former investigations focusing on Ti-6Al-4V and 52100 steel interfaces suggested an asymptotic decrease of the wear rate as a function of the contact size [20-22] (Fig. 1). 


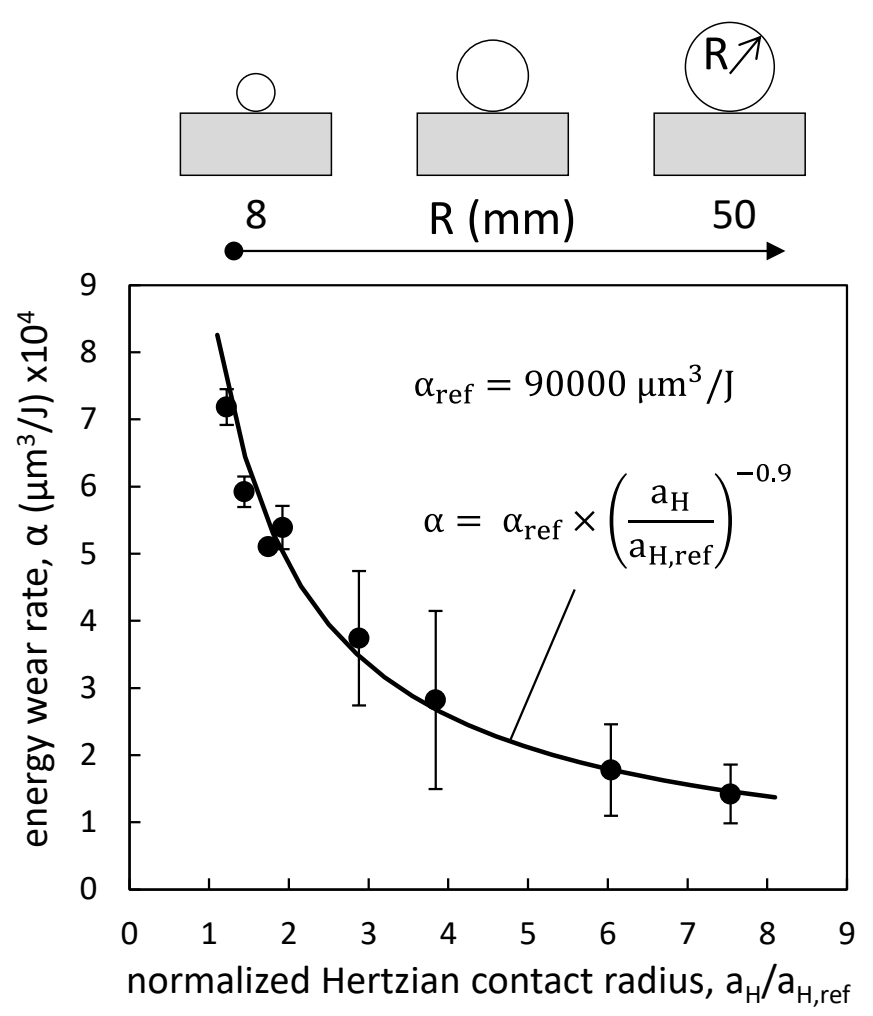

Fig. 1. Evolution of the friction energy wear rate of a sphere-on-flat 52100 steel interface as a function of the Hertzian contact radius applying a $p_{H, \max }=1100 \mathrm{MPa}$ maximum Hertzian pressure $\left(a_{\text {Href }}=0.1 \mathrm{~mm}\right)($ After [21]).

The physical interpretation of such tendency is still unclear. A first explanation was derived from the Third Body Theory (TBT). Arguing that the larger the contact size, the longer the debris path before being ejected, it was concluded that large contact, by favoring thicker protective debris layer, tends to reduce the global wear rate $[9,10,21-$ 23]. Another explanation was derived from the Contact Oxygenation Concept (COC) [24-26] suggesting that the global wear rate of a fretting contact is mainly driven by the partition between adhesive and abrasive wear zones operating within the fretted interface. Because abrasive wear displays higher wear rate (i.e. material removal rate) than adhesive one, it could be concluded that the larger the abrasive wear area in the fretting scar the higher the global wear rate. 
In fact, one can suppose that these two concepts are implied simultaneously to explain the reduction of the wear rate versus the contact size. Hence, one objective of this work is to clarify the relative influence of TBT and COC processes regarding the contact size effect on fretting wear fluctuations. An original experimental strategy involving a lowalloyed steel crossed flat-on-flat fretting contact configuration is adapted. This flat-on-flat contact not only prevents the contact area extension [27] but also allows the easy adjustment of the collinear contact length along the sliding direction $\left(\mathrm{L}_{\mathrm{C}}\right)$ as well as the transverse length to this latter $\left(\mathrm{L}_{\mathrm{T}}\right)$ (i.e. the apparent contact area is simply the product of $\mathrm{L}_{\mathrm{C}}$ by $\mathrm{L}_{\mathrm{T}}$ ). Therefore, by adjusting $\mathrm{L}_{\mathrm{C}}$ and $\mathrm{L}_{T}$ contact lengths, it appears possible to monitor independently the COC process which is assumed isotropic (i.e. driven by the minimum distance from the contact center to the open air) from the anisotropic TBT wear process which is mainly driven by the $\mathrm{L}_{C}$ collinear length (i.e. debris length path before ejection).

\section{Experimental procedure}

\subsection{Materials}

The material used in the current study is $34 \mathrm{NiCrMo16}$ which is a tempered low-alloy steel whose mechanical properties are shown in Table 1 [27].

Table 1. Mechanical properties of $34 \mathrm{NiCrMo16}$ (obtained from the documentation of material supplier [27]).

\begin{tabular}{|c|c|c|c|}
\hline Young's modulus, $\mathrm{E}(\mathrm{GPa})$ & Poisson's ratio, $\mathrm{v}$ & Yield stress $(0.2 \%), \sigma_{\mathrm{y} 0.2 \%}(\mathrm{MPa})$ & Ultimate stress,$\sigma_{\mathrm{u}}(\mathrm{MPa})$ \\
\hline 205 & 0.3 & 950 & 1130 \\
\hline
\end{tabular}




\subsection{Experimental setup and data acquisition}

Fretting tests were performed on a hydraulic actuator (Fig. 2a) which is specifically adapted to investigate large contact configurations. Experiments were performed at ambient conditions of temperature $\left(25^{\circ} \mathrm{C} \pm 5{ }^{\circ} \mathrm{C}\right)$ and humidity $(\mathrm{RH}=40 \% \pm 10 \%)$ such that the top sample is submitted to fretting displacements while keeping the bottom sample fixed. High resolution sensors permit online measurements of the tangential force $(Q)$, the tangential displacement $(\delta)$ and the normal force $(P)$ allowing tracing the $(Q-\delta)$ fretting log (Fig. 2b). In fact, the displacement amplitude $\left(\delta^{*}\right)$ (i.e. the maximum displacement in a fretting cycle) does not reflect the real contact sliding due to the tangential accommodation of the test rig. To maintain a constant sliding amplitude during fretting test, the displacement amplitude $\left(\delta^{*}\right)$ is continuously adjusted in order to keep a constant sliding amplitude $\left(\delta_{g}\right)$ which is measured when $Q=0$ (Fig. 2b). Note that the fretting displacement amplitude which is commonly expressed in micron is presently expressed in $\mathrm{mm}$ to be consistent with the contact length scale dimension.

By summing the areas of the fretting loops in the fretting log (Fig. 2c), the accumulated dissipated friction energy can be estimated (Eq. 1).

$\Sigma \mathrm{Ed}=\sum_{\mathrm{i}=1}^{\mathrm{N}} \operatorname{Ed}(\mathrm{i})$

To assess the friction evolution during fretting, an averaged energy friction coefficient $\mu_{\mathrm{e}}$ is considered (Eq. 2) [5].

$\mu_{\mathrm{e}}=\frac{\mathrm{Ed}}{4 \cdot \mathrm{P} \cdot \delta_{\mathrm{g}}}$ 
(a)

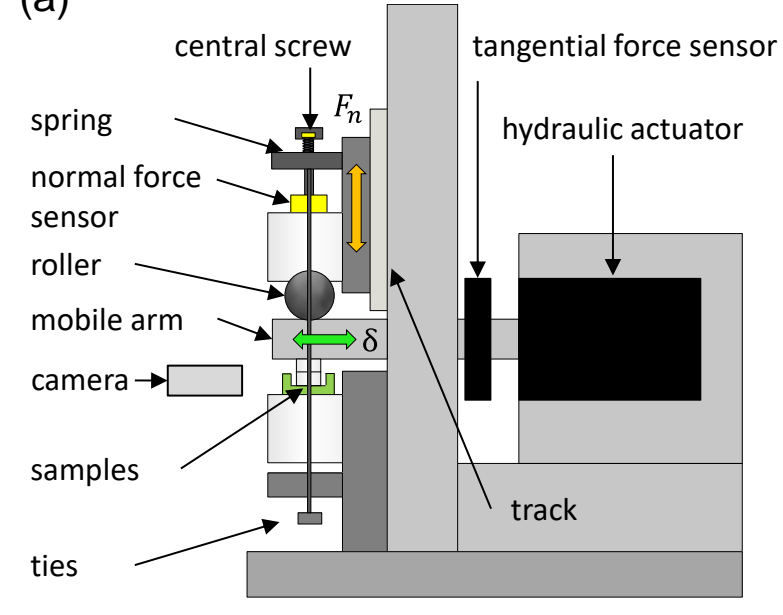

(b)

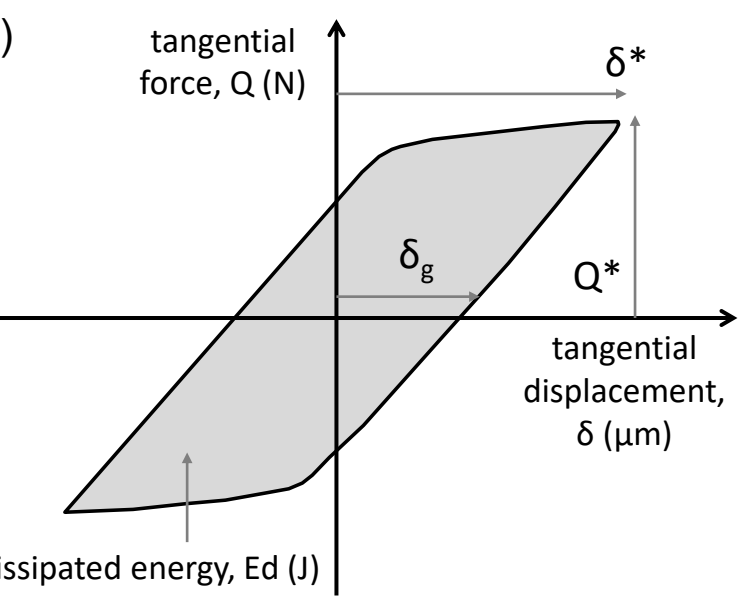

(c)

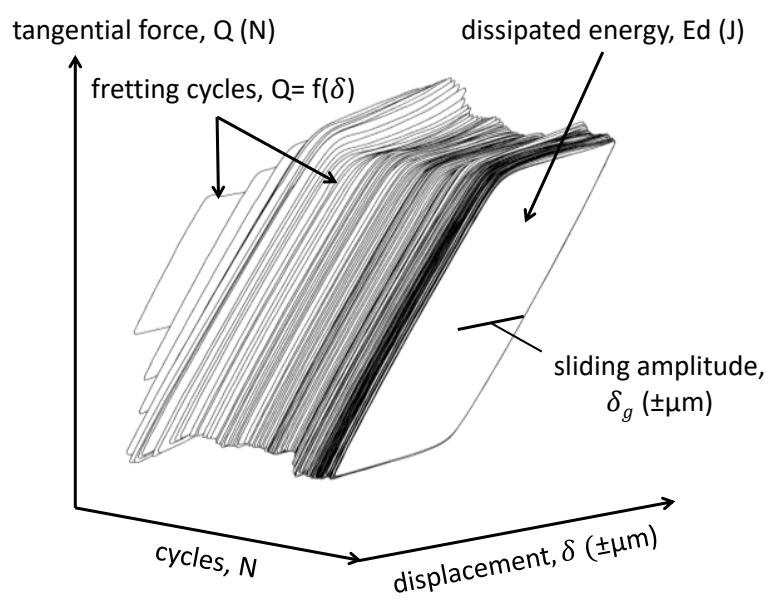

Fig. 2. Schematic presentation of the: (a) experimental horizontal hydraulic set-up; (b) gross-slip fretting cycle; and (c) fretting log with $\delta_{g}$ kept constant by monitoring $\delta^{*}$. 


\subsection{Contact geometry}

\subsubsection{Plain flat-on-flat configuration}

Fig. 3 describes the "plain" flat-on-flat (mono) contact geometry characterized by a rectangular contact area " $\mathrm{A}=\mathrm{L}_{\mathrm{C}} \times \mathrm{L}_{\mathrm{T}}$ " such that " $\mathrm{L}_{\mathrm{C}}$ " is the longitudinal contact length collinear with the sliding direction $(\delta)$ and " $\mathrm{L}_{\mathrm{T}}$ " is the transverse contact length perpendicular to the sliding direction $(\bar{\delta})$. However, due to technical aspects related to the stability and the alignment of the fretted interface, mono-contact configurations cannot allow testing $\mathrm{L}_{\mathrm{C}}$ or $\mathrm{L}_{\mathrm{T}}$ values lower than $2 \mathrm{~mm}$. To investigate lower $\mathrm{L}_{\mathrm{C}}$ or $\mathrm{L}_{\mathrm{T}}$ values, an original macro-texturation strategy is applied.
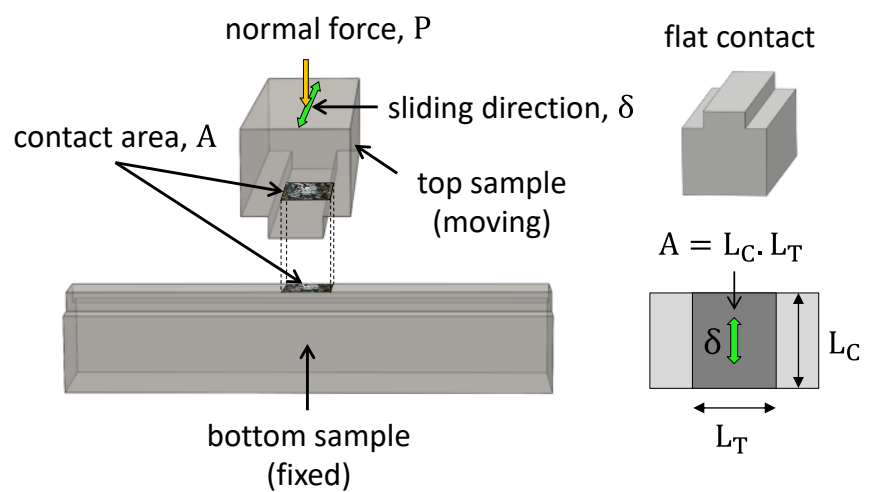

(fixed)

Fig. 3. Schematic illustration of the studied crossed plain flat-on-flat contact geometry and the associated contact sizes $\left(\mathrm{L}_{\mathrm{C}}\right.$ and $\left.\mathrm{L}_{\mathrm{T}}\right)$ where the top sample is moving and the bottom sample is fixed.

2.3.2 Textured samples: access to smaller contact sizes

The investigation of third body flows and contact oxygenation at very small contact sizes is achieved by texturing bottom samples while keeping the top samples plain (untextured). The texturation method involves machining rectangular grooves on the plane surface of the bottom specimens in order to evacuate the third body particles and 
consequently control their influence on the friction and wear response (Fig. 4a). The grooves thickness $\left(\mathrm{L}_{\mathrm{G}}\right)$ and the depth (D) are maintained constant at 0.5 and $1 \mathrm{~mm}$ respectively (Fig. 4a). Using this macro-texturation procedure, $\mathrm{L}_{\mathrm{T}}$ lengths ranging from 0.5 to $2.5 \mathrm{~mm}$ while fixing $\mathrm{L}_{\mathrm{C}}=\mathrm{L}_{\mathrm{ref}}=5 \mathrm{~mm}$ were investigated. This " $\mathrm{L}_{\mathrm{T}}$ " test procedure is combined with an equivalent " $\mathrm{L}_{C}$ " experimental analysis where $\mathrm{L}_{C}$ is varied from 0.75 to $2.25 \mathrm{~mm}$ while $\mathrm{L}_{\mathrm{T}}$ is kept constant at $\mathrm{L}_{\mathrm{ref}}=5 \mathrm{~mm}$. The shift between " $\mathrm{L}_{\mathrm{T}}$ " and " $\mathrm{L}_{\mathrm{C}}$ " experiments is simply obtained by adjusting the orientation of the bottom (fixed) specimen versus the top moving untextured specimen as detailed in Fig. 4. Note that $\mathrm{L}_{\mathrm{C}}=0.5 \mathrm{~mm}$ experiments were excluded from the analysis due to flexural fatigue failure of the textured surface. The nominal contact area of the textured surface is estimated using the following expression substituting $\mathrm{L}_{\mathrm{T}}$ or $\mathrm{L}_{\mathrm{C}}$ in the variable $\mathrm{X}$ such that:

If $\mathrm{L}_{\mathrm{ref}}-\operatorname{Ent}\left(\frac{\mathrm{L}_{\mathrm{ref}}}{\left(\mathrm{X}+\mathrm{L}_{\mathrm{G}}\right)}\right) \times\left(\mathrm{X}+\mathrm{L}_{\mathrm{G}}\right)<\mathrm{X}$ then

$A=\left(\left(\operatorname{Ent}\left(\frac{L_{r e f}}{\left(X+L_{G}\right)}\right)\right) \times X+L_{r e f}-\operatorname{Ent}\left(\frac{L_{r e f}}{\left(X+L_{G}\right)}\right) \times\left(X+L_{G}\right)\right) \times L_{r e f}$

Else, $\mathrm{A}=\left(\left(\operatorname{Ent}\left(\frac{\mathrm{L}_{\mathrm{ref}}}{\left(\mathrm{X}+\mathrm{L}_{\mathrm{G}}\right)}\right)+1\right) \times \mathrm{X}\right) \times \mathrm{L}_{\mathrm{ref}}$

If $\mathrm{X}=\mathrm{L}_{\text {ref }}$ then $\mathrm{A}=\mathrm{A}_{\text {ref }}=\mathrm{L}_{\text {ref }} \times \mathrm{L}_{\text {ref }}$

Finally, the normal force $\mathrm{P}(\mathrm{N})$ is adjusted in a way to maintain a constant mean contact pressure at a desired value $\mathrm{p}=100 \mathrm{MPa}$ whatever the contact configuration such that:

$\mathrm{P}=\mathrm{A} \times \mathrm{p}$ 
(a) normal force, $\mathrm{P}$

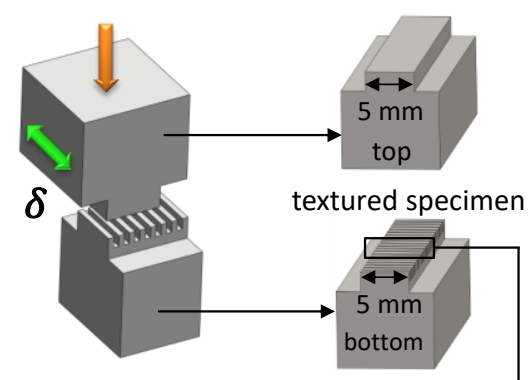

rectangular pads (textures) grooves

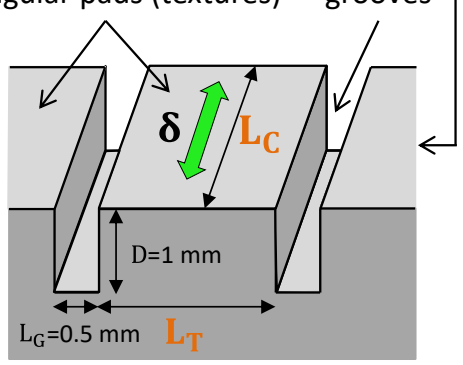

(b)
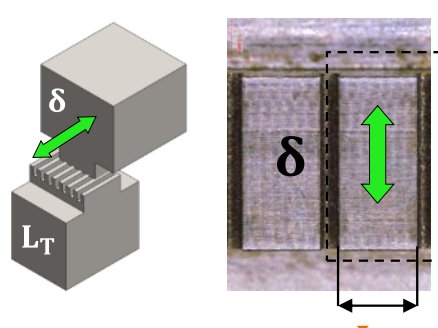

$\mathrm{L}_{\mathrm{T}}$

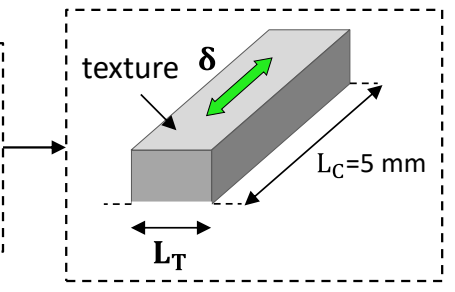

$\mathrm{L}_{\mathrm{T}} \in[0.5 \mathrm{~mm}, 2.25 \mathrm{~mm}]$

Variable $\mathbf{L}_{\mathbf{C}}$
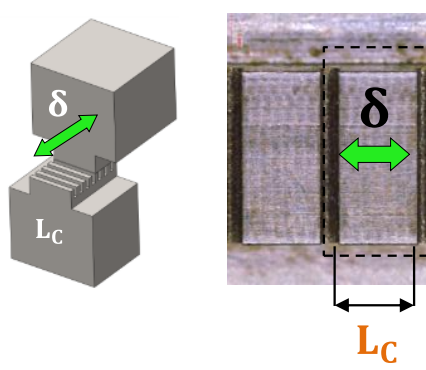

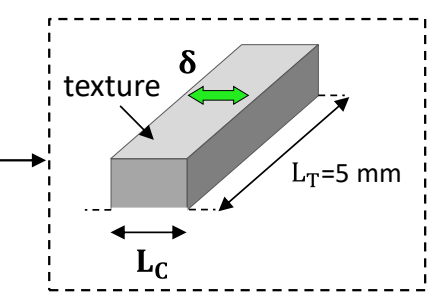

$\mathrm{L}_{\mathrm{C}} \in[0.75 \mathrm{~mm}, 2.25 \mathrm{~mm}]$

Fig. 4. (a) Crossed flat-on-flat configuration with textured bottom samples; (b) geometrical description of the textures orientation with respect to the sliding direction where the top sample is moving parallel to the grooves in case of variable $\mathrm{L}_{\mathrm{T}}$ or perpendicular to them in case of variable $\mathrm{L}_{\mathrm{C}}$ while keeping the bottom sample fixed.

\subsubsection{Test procedure}

Fig. 5 illustrates the given multi-scale experimental strategy combining both plain and macro-textured crossed flat contact configurations. Several tests were done starting from a reference plain contact (repeated three times) having a contact pressure $p_{\text {ref }}=100$ MPa, number of cycles $N_{\text {ref }}=20000$, sliding frequency $f_{\text {ref }}=1 \mathrm{~Hz}$, sliding amplitude $\delta_{g, \text { ref }}= \pm$ $0.1 \mathrm{~mm}$, and a square apparent contact area $A_{\text {ref }}=25 \mathrm{~mm}^{2}\left(\mathrm{~L}_{\mathrm{C}}=\mathrm{L}_{\mathrm{T}}=5 \mathrm{~mm}\right)$. Keeping constant $p, N$ and $\delta_{g}$ at these reference conditions, $L_{T}$ and $L_{C}$ were then adjusted from 5 to $0.5 \mathrm{~mm}$ to undertake " $\mathrm{L}_{\mathrm{T}}$ " and " $\mathrm{L}_{\mathrm{C}}$ " experiments as detailed previously (Fig. 5a). 
Then, a specific set of experiments will be done varying $\delta_{\mathrm{g}}$ from $\pm 0.025 \mathrm{~mm}$ to $\pm 0.2 \mathrm{~mm}$ while $\mathrm{L}_{\mathrm{T}}=\mathrm{L}_{\mathrm{C}}=\mathrm{L}_{\mathrm{ref}}$ to establish coupled interactions between $\mathrm{L}_{\mathrm{C}}$ and $\delta_{\mathrm{g}}$.
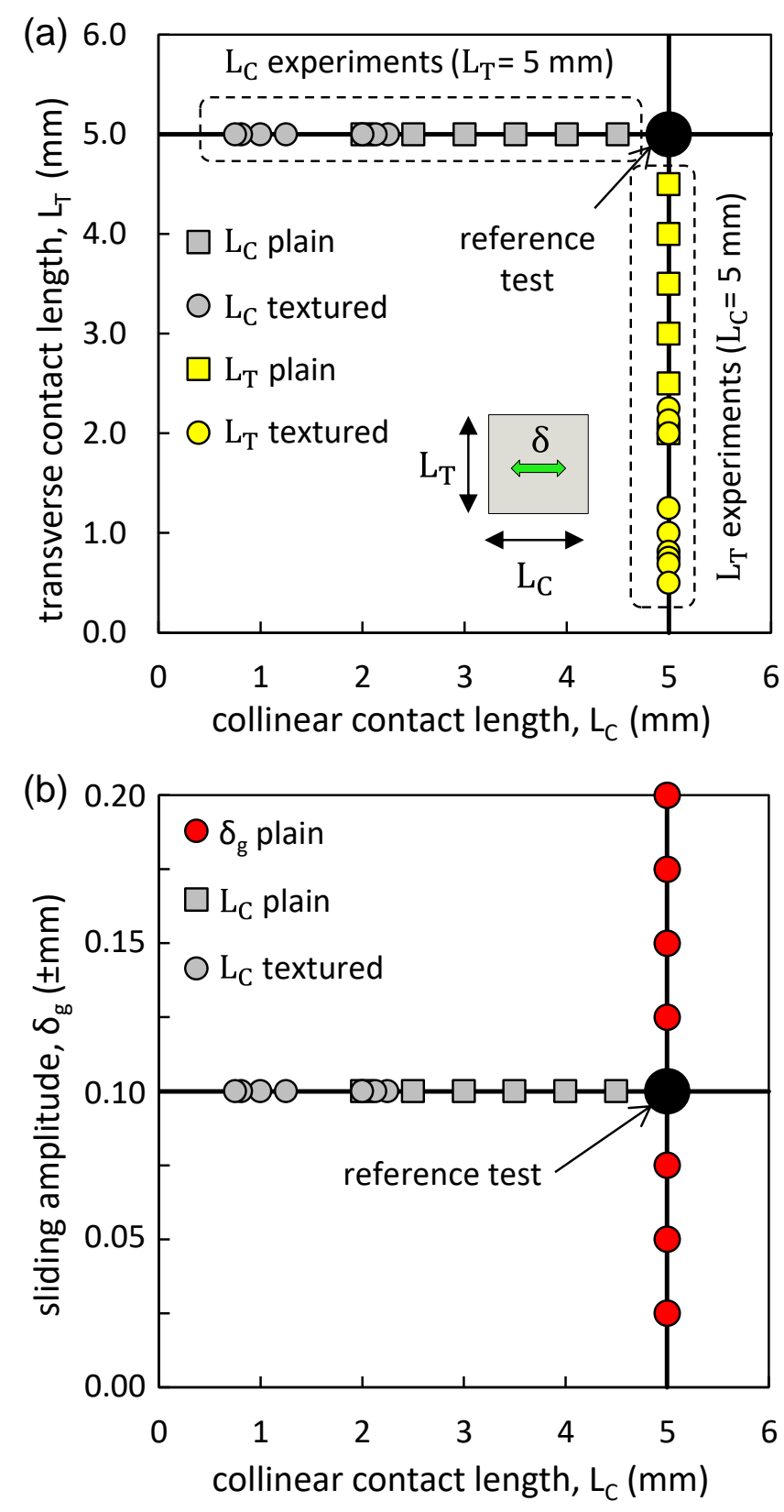

Fig. 5. Multi-scale experimental test strategy showing the selected geometrical and sliding parameters: (a) " $\mathrm{L}_{\mathrm{T}}$ " versus " $\mathrm{L}_{\mathrm{C}}$ " $\left(\delta_{\mathrm{g}}=0.1 \mathrm{~mm}\right)$; (b) sliding amplitude " $\delta_{\mathrm{g}}$ " versus " $\mathrm{L}_{\mathrm{C}}$ " $\left(\mathrm{L}_{\mathrm{T}}=5 \mathrm{~mm}\right)$ $\left(\mathrm{N}_{\text {ref }}=20000\right.$ cycles, $p_{\text {ref }}=100 \mathrm{MPa}$, and $\left.\mathrm{f}_{\mathrm{ref}}=1 \mathrm{~Hz}\right)$. 


\subsection{Wear volume analysis}

To evaluate surface topography after wear damage, the top and bottom samples are ultrasonically cleaned for 20 minutes to eliminate the remaining debris particles. Then, 3D fretting scars are acquired using interferometric profilometry (Fig. 6). 2D wear profiles can be obtained by averaging the 3D profiles on the transverse length.

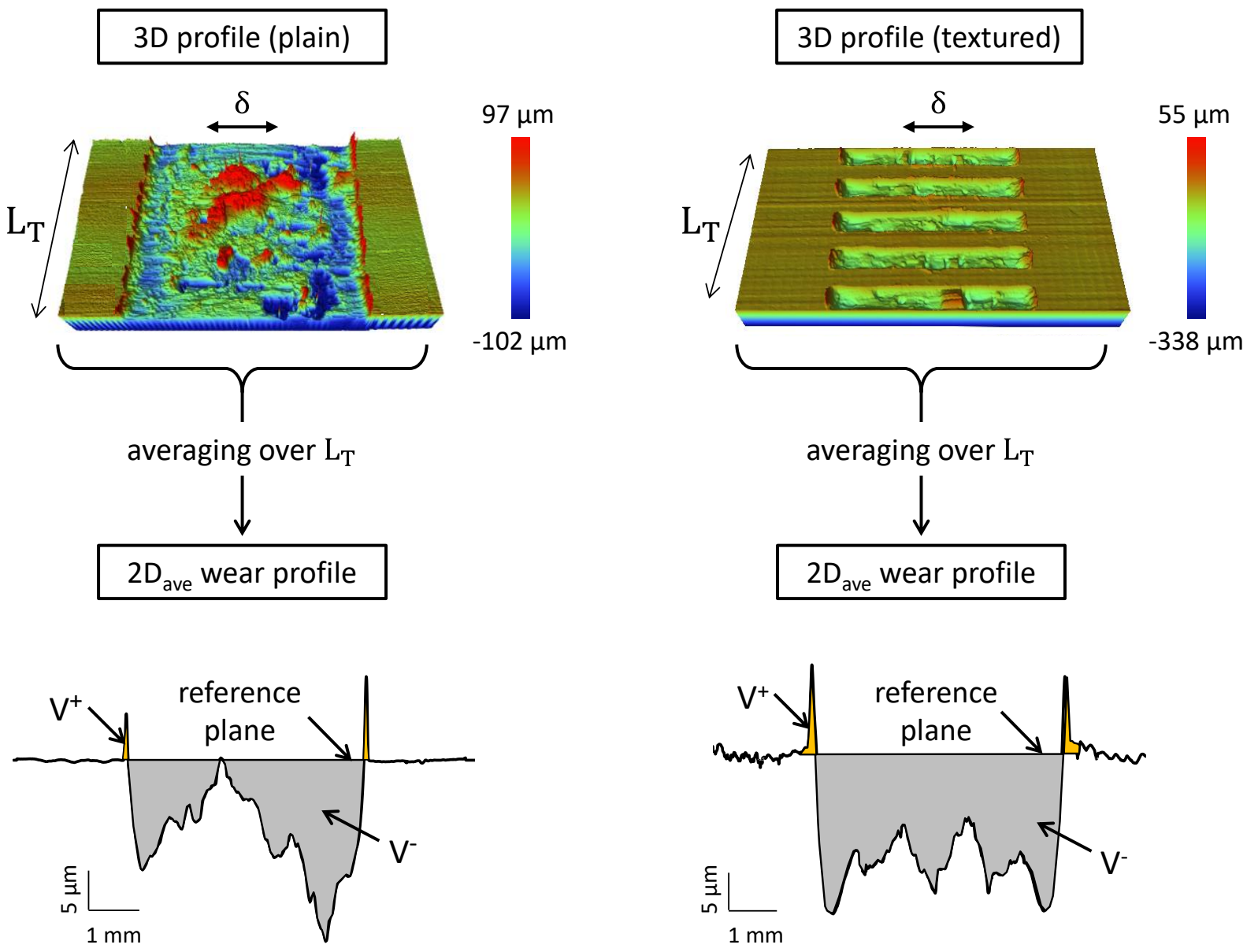

Fig. 6. 3D and 2D wear profiles of the worn samples obtained by 3D interferometric profilometry of the top samples in plain and textured specimens. 
By defining a reference plane, the wear volume is calculated from the difference between the volumes below and above the reference plane denoted by $\mathrm{V}^{-}$and $\mathrm{V}^{+}$ respectively (Eq. 5) [27].

$\mathrm{V}_{\mathrm{t}}=\mathrm{V}^{-}-\mathrm{V}^{+}$

By summing the wear volumes of the top and bottom samples, the total wear volume $\mathrm{V}$ can be calculated (Eq. 6).

$\mathrm{V}=\mathrm{V}_{\mathrm{t}}$ (top) $+\mathrm{V}_{\mathrm{t}}$ (bottom)

\section{Results}

\subsection{Grooves' fill-up mechanism}

One advantage of the textured samples is the possibility of the online observation of the grooves' fill-up process by the debris particles generated within the lateral fretted interface. In Fig. 7, series of images were taken for a contact configuration having $L_{T}=2$ $\mathrm{mm}\left(\mathrm{L}_{\mathrm{C}}=5 \mathrm{~mm}\right)$. Note that good-resolution transverse observations are currently, not possible due to the presence of mechanical components, required to apply the normal load (see Fig. 2a). It appears that the first oxide debris particles are ejected around 100 cycles. Besides, the grooves are completely filled between 1000 and 5000 cycles (Fig. 7a). However, debris particles undergo continuous compaction after 5000 cycles till the end of the test due to the continuous creation and ejection of debris to the grooves. Interestingly, whatever the textures size, the groove fill-up mechanism is generally the same and can be summarized by the following (1) to (9) steps as illustrated in Fig. 7. 


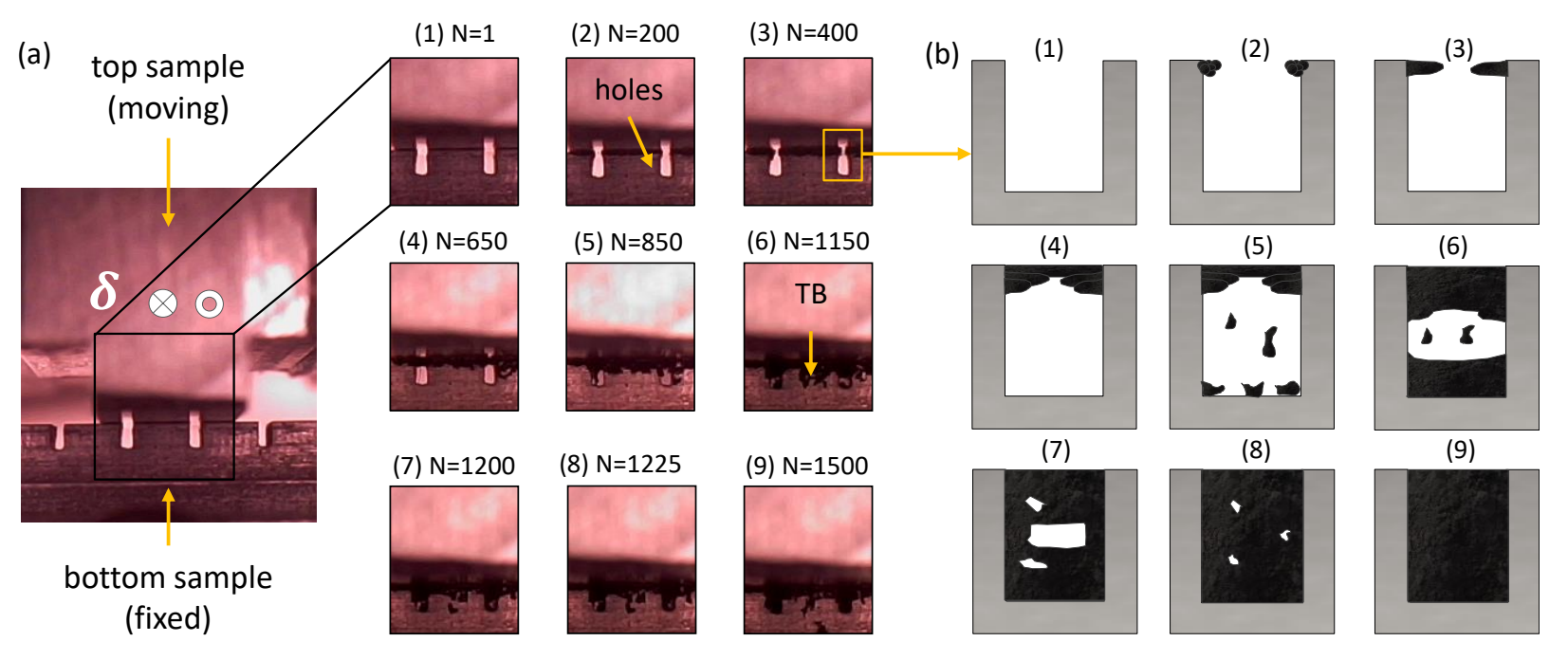

Fig. 7. (a) Camera acquisitions showing grooves' fill-up mechanism obtained from textured samples with $\mathrm{L}_{\mathrm{T}}=2 \mathrm{~mm}$, and $\mathrm{L}_{\mathrm{C}}=5 \mathrm{~mm}$, for $\mathrm{N}=20000$ cycles, $\mathrm{p}=100 \mathrm{MPa}, \delta_{\mathrm{g}}= \pm 0.1 \mathrm{~mm}$ and $\mathrm{f}=1$ $\mathrm{Hz}$. (b) Schematic illustration of the grooves' fill-up mechanism: (1) initial stage; (2) ejection of debris particles; (3) agglomeration of debris particles on the top; (4) formation of a bridge of agglomerated debris on the top; (5) collapse and fall of some debris particles to the bottom; (6) accumulation of debris particles at the bottom; (7) clustering of debris particles on the top and bottom; (8) fill up of the hole with uncompact debris; (9) continuous compaction of the debris filling the hole.

During the first few cycles, metal-metal interaction takes place leading to an increase in the coefficient of friction (1). Around the first 100 cycles, and once the metal-metal interaction becomes intense, the first debris particles are ejected out of the contact (2) leading to a decrease in the coefficient of friction due to the accommodating effect of the debris entrapped between the contacting first bodies. Then, the debris particles start to agglomerate on the topside of the groove from the edges towards the center (3) until clustering into a bridge which is detected between 278 and 698 cycles (4). Due to the applied normal load, the gravitational forces, and the powdery form of wear particles, the freshly formed debris will push the older conglomerates downside which will collapse into smaller particles that will occupy the bottom side of the grooves (5). 
Following this, debris particles start to accumulate on the bottom side of the grooves (6) until reaching a state where the latter form big clusters on the top and the bottom sides of the groove (7). In step (8), the groove will be thoroughly filled with uncompact debris particles. Under the influence of applied loads and the continual production of debris particles, the groove will be entirely filled with continuously compacting conglomerates.

It is noteworthy that similar observations were reported for the stages (1) to (4) by a previous study [28] which was carried out using closed laser-textured micro-pores. The fact of having opened and relatively large grooves appears as an advantage in the current study which helped establish a complete grooves' fill-up process from stage (1) to (9).

SEM observations of the third body reveal the presence of a significant amount of powdery agglomerating particles (Fig. 8a \& b). Fig. 8c shows an example of a plate-like sheet having a thickness of $2.53 \mu \mathrm{m}$ embedded within the ejected particles which might be one of the precursors of powdery particles.

One important conclusion of this investigation is that the debris accumulated within the grooves displays a powdery structure such that even when the grooves are fully fed up, an easy access of oxygen molecules through the longitudinal grooves will allow an easier contact oxygenation of the contacted surfaces. Hence, by varying $\mathrm{L}_{\mathrm{T}}$ contact length it will be possible to monitor the contact oxygenation process of the interface. 

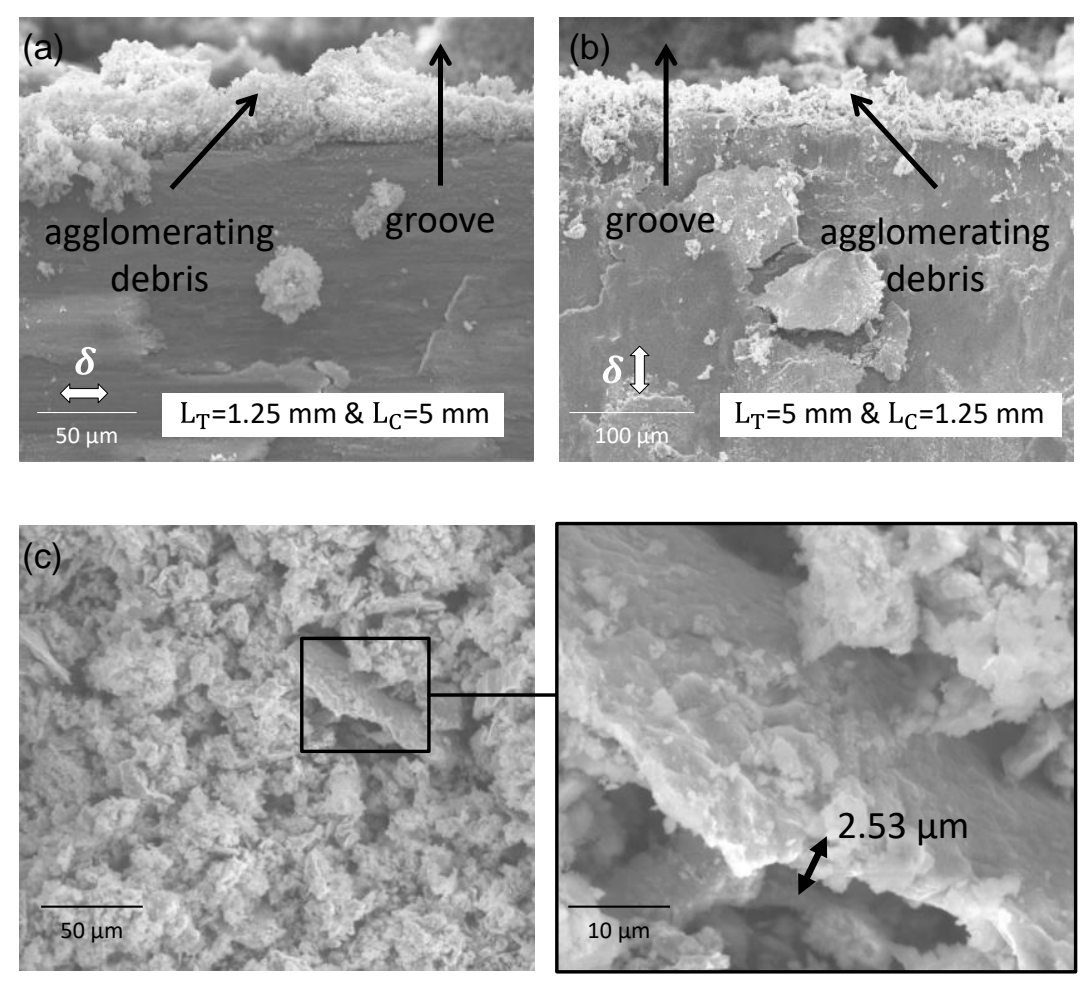

Fig. 8. SEM observations of the agglomerated powdery debris at the borders of the contact in: (a) textured sample with $\mathrm{L}_{\mathrm{T}}=1.25 \mathrm{~mm}$ and $\mathrm{L}_{\mathrm{C}}=5 \mathrm{~mm}$ (before cleaning with ethanol); and (b) the textured sample with $\mathrm{L}_{\mathrm{T}}=5 \mathrm{~mm}$ and $\mathrm{L}_{\mathrm{C}}=1.25 \mathrm{~mm}$ (before cleaning with ethanol). (c) $\mathrm{SEM}$ and BSE observations of a thin wear sheet (platelet) embedded in the ejected third body outside the grooves in a textured sample with $\mathrm{L}_{\mathrm{T}}=1.25 \mathrm{~mm}$, and $\mathrm{L}_{\mathrm{C}}=5 \mathrm{~mm}(\mathrm{~N}=20000$ cycles, $\mathrm{p}=100 \mathrm{MPa}$, $\delta_{g}= \pm 0.1 \mathrm{~mm}$ and $\left.\mathrm{f}=1 \mathrm{~Hz}\right)$.

\subsection{Friction evolution}

Fig. 9a shows the evolution of the energy friction coefficient " $\mu_{\mathrm{e}}$ " with the number of cycles at the reference conditions. The coefficient of friction increases significantly during the first 100 cycles (I). Following this, the coefficient of friction decreases (II), and starts increasing again before 500 cycles (III) to achieve a stable evolution beyond 5000 cycles (IV). 

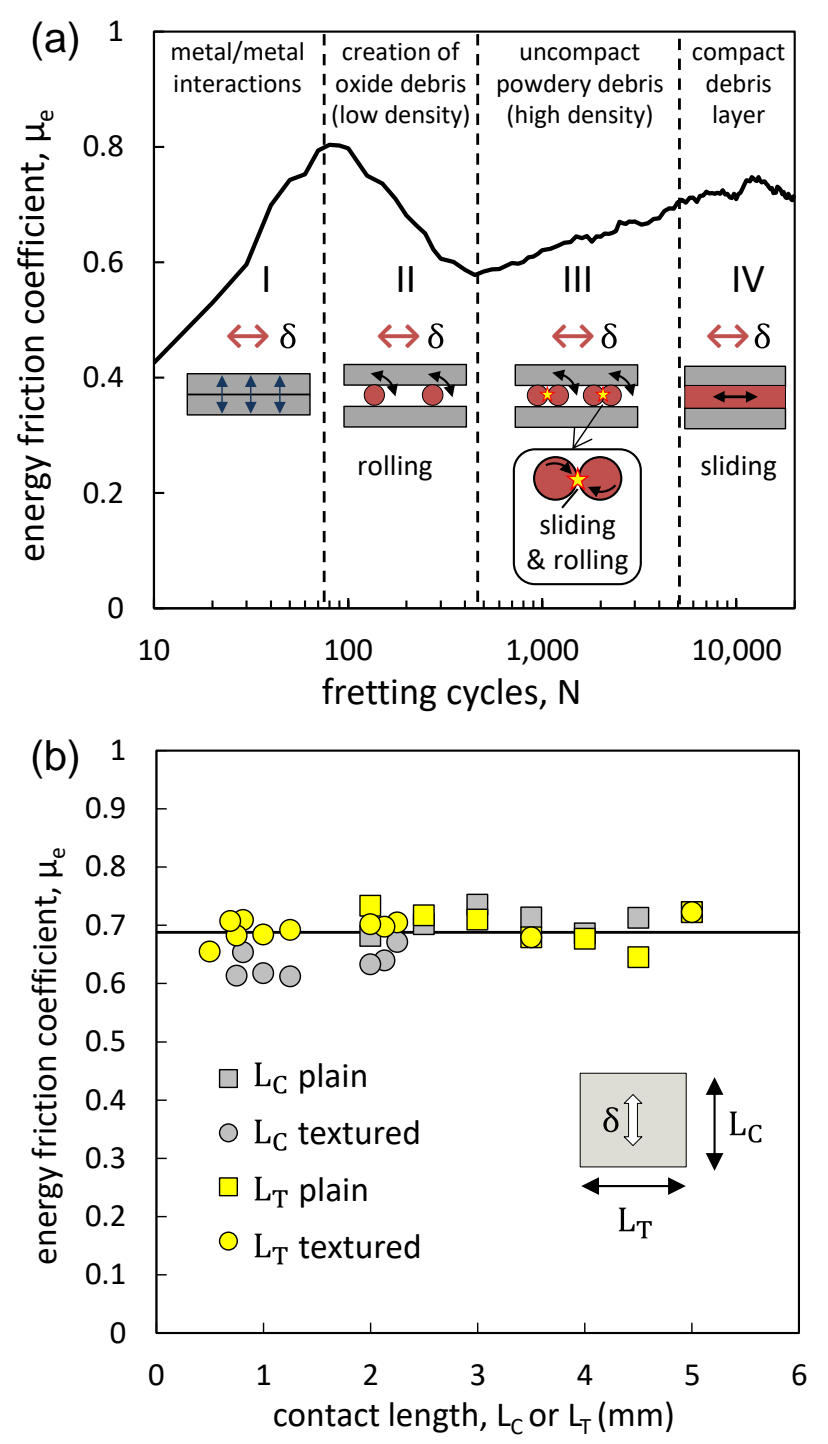

Fig. 9. Variation of the energy friction coefficient $\mu_{\mathrm{e}}$ as function of the (a) number of cycles at the reference condition and (b) the contact lengths $\mathrm{L}_{C}$ or $\mathrm{L}_{T}$ such that $\mathrm{L}_{C}=5 \mathrm{~mm}$ if $\mathrm{L}_{T}$ varies and $\mathrm{L}_{\mathrm{T}}=5 \mathrm{~mm}$ if $\mathrm{L}_{\mathrm{C}}$ varies $\left(\mathrm{N}=20000\right.$ cycles, $\mathrm{p}=100 \mathrm{MPa}, \delta_{\mathrm{g}}= \pm 0.1 \mathrm{~mm}$ and $\left.\mathrm{f}=1 \mathrm{~Hz}\right)$.

These four stages are attributed to the third body behavior at the interface as discussed in $[21,22,27]$. During the first 100 cycles, the elimination of native oxides and the increase in the metal-metal interaction cause a fast increase in the coefficient of friction until a maximum value. Following this, debris particles are generated within the interface supporting a significant part of the applied stresses hence lowering the friction 
coefficient by rolling accommodation. The friction coefficient decreases then to a minimum value. However, with the wear extension, the density of oxides debris entrapped within the interface increases promoting an increase in the sliding interactions between the rolling particles and a continuous increase of the global friction value [22]. This increase continues until a relatively compact debris bed is obtained after reaching equilibrium between the debris formation and ejection flows leading to a stable friction coefficient controlled by shear and sliding accommodations. The interpretation of the friction coefficient evolution comes in agreement with the camera observations (Fig. 8) and more particularly with the occurrence of platelet debris structure after stage 3.

By comparing the energy friction coefficient averaged over the entire test duration for variable " $\mathrm{L}_{\mathrm{C}}$ " and " $\mathrm{L}_{\mathrm{T}}$ " (Fig. 9b), it appears that there is no substantial difference in $\mu_{\mathrm{e}}$ which has a global average value equals to $0.69 \pm 0.04$. This suggests that for the studied conditions, the friction response seems independent of the contact area and the contact orientation with respect to the sliding direction. Note that the evolution of $\mathrm{L}_{\mathrm{C}}$ and $\mathrm{L}_{\mathrm{T}}$ promotes a significant fluctuation of the contact oxygenation condition and the related partitions between adhesive and abrasive wear areas. It can be therefore concluded that the local friction coefficients operating in these adhesive and abrasive wear areas are in fact quite similar or at least not sufficiently different to induce a fluctuation of the global friction coefficient. It should be noted that lower friction coefficient values are observed for the shortest $\mathrm{L}_{\mathrm{C}} \leq 1.25 \mathrm{~mm}$ textured surfaces. This could be induced by a bending accommodation of the contact which tends to decrease the friction dissipation and consequently reduce the energy friction coefficient. 


\subsection{Wear kinetics}

Fig. 10 displays the evolution of the wear volume extension as a function of the accumulated friction energy of the studied test conditions. A very dispersive distribution is observed. No linear relationship can be derived to extract a single energy wear coefficient. This indirectly underlines the significant effect of the contact size (i.e. " $\mathrm{L}_{\mathrm{C}}$ " and " $\mathrm{L}_{\mathrm{T}}$ " lengths) and the sliding amplitude on the fretting wear rate fluctuations at least for the studied interface.

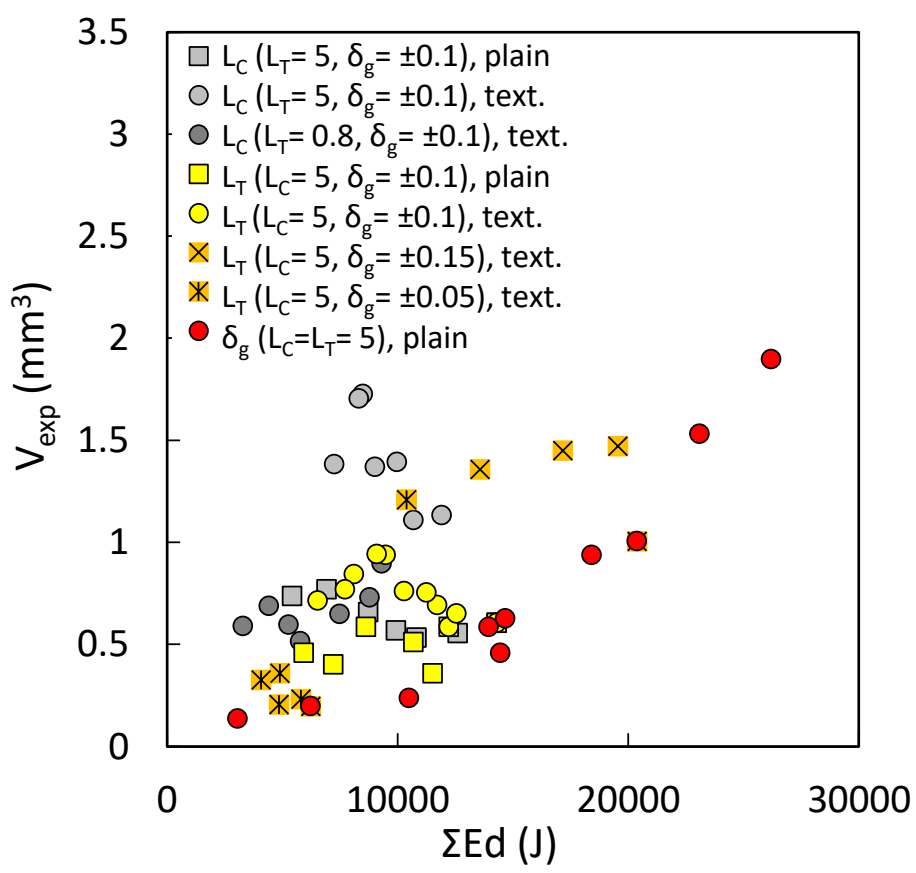

Fig. 10. Evolution of the wear volume as function of the accumulated friction energy at different test conditions by varying $L_{C}, L_{T}$ and $\delta_{g}(N=20000$ cycles, $p=100 \mathrm{MPa}$ and $f=1 \mathrm{~Hz})$. (Nomenclature: $\mathrm{L}_{C}$ (grey): varying $\mathrm{L}_{C}$ with $\mathrm{L}_{T}=5 \mathrm{~mm} ; \mathrm{L}_{T}$ (yellow): varying $\mathrm{L}_{T}$ with $\mathrm{L}_{C}=5 \mathrm{~mm} ; \delta_{g}$ (red) varying $\delta_{g}$ with $L_{T}=L_{C}=5 \mathrm{~mm}$ (plain: plain specimens; text.: textured specimens).

3.3.1 Influence of $\mathrm{L}_{\mathrm{C}}$ and $\mathrm{L}_{\mathrm{T}}$ contact lengths on the wear rate 
A more elaborated fretting wear model needs to be considered. To do so, the "individual" energy wear rate is estimated for each experiment such that:

$\alpha=\frac{\Delta \mathrm{V}}{\Delta \sum \mathrm{Ed}}$

This friction energy wear-rate analysis is established assuming that a steady state wear regime is already operating for the 20000 cycles test duration. This hypothesis was previously confirmed in [27] where, for similar contact conditions, a linear increase of the wear volume versus the fretting cycles (or the friction energy) was observed above 5000 cycles. It is also confirmed by the stable evolution of the friction coefficient observed above 5000 cycles as illustrated in Fig. 9.

Fig.11 plots the evolution of the energy wear rate $\alpha$ by varying $\mathrm{L}_{C}$ and $\mathrm{L}_{T}$. Confirming former investigations [22], increasing $\mathrm{L}_{\mathrm{C}}$ or $\mathrm{L}_{\mathrm{T}}$ contact size parameters induces an asymptotic decrease in the friction energy wear rate toward the reference test condition $\left(\alpha_{\text {ref }}=4.23 \times 10^{-5} \mathrm{~mm}^{3} / \mathrm{J}\right)$ which corresponds to the contact size $\left(\mathrm{L}_{\mathrm{C}}=\mathrm{L}_{\mathrm{T}}=5 \mathrm{~mm}\right)$ (Fig.11). At this stage of the current investigation, it is still unclear if the energy wear rate will converge definitively to zero or to a finite value as suggested by previous works [20]. This aspect will be detailed more deeply in the discussion. Two separate evolutions can be observed suggesting that the relative influence of the collinear length regarding the wear rate fluctuation is higher than the transverse one. 


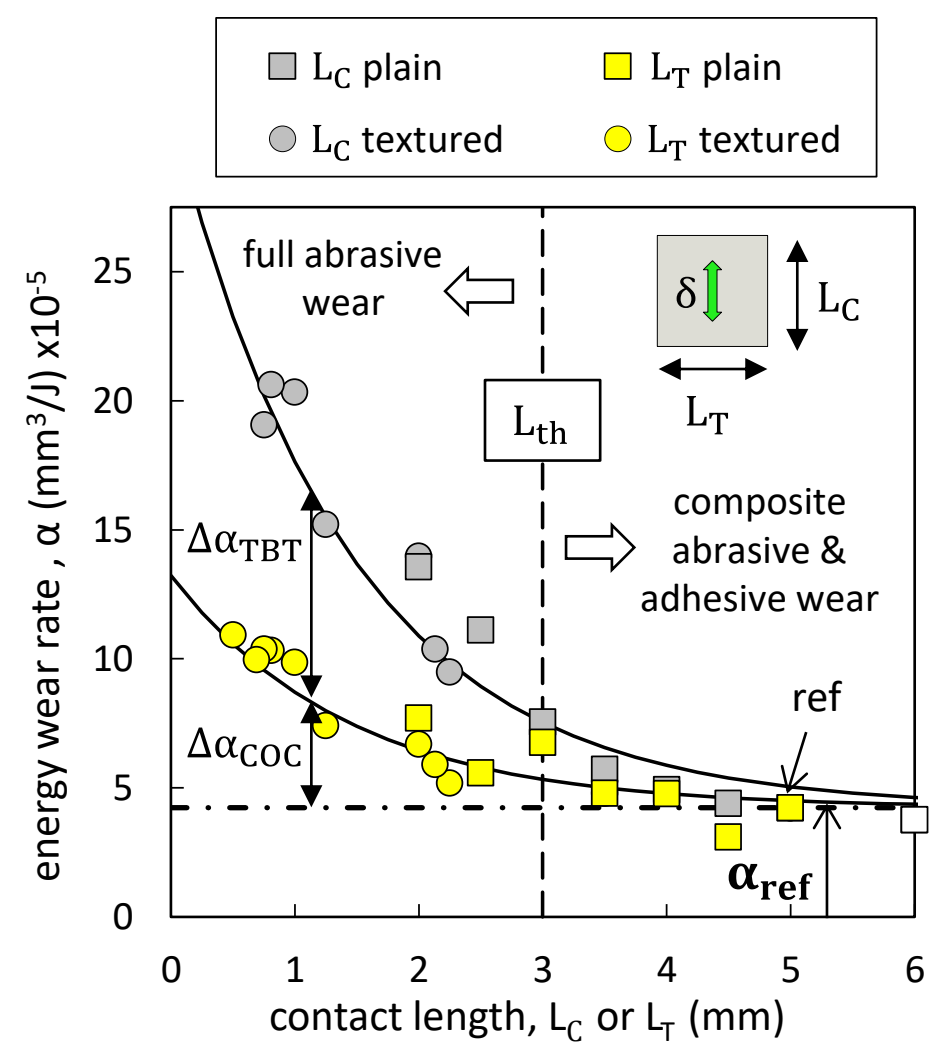

Fig. 11. Comparison of the energy wear rate as function of the contact lengths $L_{C}$ or $L_{T}$ such that $\mathrm{L}_{T}=5 \mathrm{~mm}$ if $\mathrm{L}_{C}$ varies and $\mathrm{L}_{C}=5 \mathrm{~mm}$ if $\mathrm{L}_{T}$ varies $\left(\mathrm{N}=20000\right.$ cycles, $p=100 \mathrm{MPa}, \delta_{g}= \pm 0.1 \mathrm{~mm}$ and $\mathrm{f}=1 \mathrm{~Hz})$. The wear rate at the reference conditions is $\alpha_{\mathrm{ref}}\left(\mathrm{L}_{\mathrm{C}}=\mathrm{L}_{\mathrm{T}}=5 \mathrm{~mm}\right)=4.2310^{-5} \mathrm{~mm}^{3} / \mathrm{J}$. The transition from pure abrasive to composite abrasive-adhesive wear response is detected at $\mathrm{L}_{\mathrm{th}}=3 \mathrm{~mm}$.

This result is quite interesting since maintaining the same contact area, increasing $L_{C}$ from 0.75 to $5 \mathrm{~mm}$ while fixing $\mathrm{L}_{\mathrm{T}}$ at $5 \mathrm{~mm}$ decreases the wear rate by a factor of 4 . On the other hand, by increasing $\mathrm{L}_{\mathrm{T}}$ from 0.5 to $5 \mathrm{~mm}$ while fixing $\mathrm{L}_{\mathrm{C}}$ at $5 \mathrm{~mm}$, the wear rate decreases by a factor of 2 . Finally, the fretting scar analysis suggests a transition from pure abrasive to composite abrasive-adhesive wear response when the minimum value between $\mathrm{L}_{\mathrm{T}}$ and $\mathrm{L}_{\mathrm{C}}$ falls below $\mathrm{L}_{\text {th }}=3 \mathrm{~mm}$. 


\subsection{Identification of the representative contact length scales}

The asymptotic decrease of the wear rate versus the contact sizes $\mathrm{L}_{C}$ and $\mathrm{L}_{T}$ can be explained by two principal approaches namely the Contact Oxygenation Concept (COC) and the Third Body Theory (TBT). Indeed, by reducing the distance between the contact center and the outer environment, oxygen will have easier access to the interface causing more abrasion and progressive regression of adhesive wear triggering higher wear rate according to "COC" approach [24,25,27,29] (Fig. 12 \& 13). Even under pure abrasive wear condition $\left(\mathrm{L}_{\mathrm{C}}\right.$ or $\left.\mathrm{L}_{\mathrm{T}}<\mathrm{L}_{\mathrm{th}}\right)$, a better contact oxygenation, by increasing the oxide film thickness, can explain the higher wear rate as suggested by oxidational wear models $[30,31]$. Alternatively, as mentioned by the third body theory (TBT), a reduction of the $\mathrm{L}_{\mathrm{C}}$ by reducing the debris residence time within the interface will favor the debris ejection process out of the contact promoting an increase in the wear rate. This aspect will be clarified in this section by establishing a pertinent length scale parameter monitoring both $\mathrm{COC}$ and TBT processes.

\subsubsection{COC length scale parameter}

Fig.12 compares the fretting scar morphologies of the plain contact configuration by varying $\mathrm{L}_{\mathrm{C}}$ from 2.5 to $5 \mathrm{~mm}$ (i.e. keeping constant $\mathrm{L}_{\mathrm{T}}=5 \mathrm{~mm}$ ). The optical observations confirm that most of the oxide worn debris is ejected along the sliding direction perpendicular to the "front edge". The comparison of the EDX mappings suggests that for $\mathrm{L}_{\mathrm{C}}$ smaller than $3 \mathrm{~mm}$ the whole fretted interface is covered with oxide debris which implies a full abrasive wear process. 




Fig. 12. Evolution of the debris ejection (TBT) (optical images) and the contact oxygenation (COC) (EDX maps) as a function of the contact length $\mathrm{L}_{\mathrm{C}}(\mathrm{N}=20000$ cycles, $\mathrm{p}=100 \mathrm{MPa}$, $\delta_{\mathrm{g}}= \pm 0.1 \mathrm{~mm}, \mathrm{f}=1 \mathrm{~Hz}$ and $\mathrm{L}_{\mathrm{T}}=5 \mathrm{~mm}$ ).

However, by increasing $\mathrm{L}_{\mathrm{C}}$, an adhesive wear domain displaying a low oxygen concentration can be observed in the inner part of the contact. The larger is the $\mathrm{L}_{\mathrm{C}}$, the larger is the inner adhesive wear domain leading to a composite fretting scar characterized by an inner adhesion domain surrounded by an abrasive wear annulus on the lateral borders.

This typical inner adhesive wear extension can be explained considering the COC [24,32] suggesting that di-oxygen partial pressure which is maximum on the lateral borders tends to decrease inside the contact due to the balance between the advectiondispersion-reaction processes [32] (Fig. 13). When the oxygen partial pressure falls 
below a threshold value (i.e. $\mathrm{P}_{\mathrm{O}, \text { th }}=0.1 \mathrm{~Pa}$ ) [30-32], metal oxidation is no more possible and adhesive wear inducing direct metal-metal interactions can be observed.

As suggested by the fretting scar EDX mapping (Fig. 12), the extension of the lateral oxide corona (i.e. well oxygenated interface) is quasi-isotropic whatever the sliding orientation. Assuming a constant friction power density condition (i.e. reaction rate), the smaller the distance of the inner part from the open air, the smaller the inner adhesion zone (Fig. 13). Therefore, the pertinent COC contact length scale could be related to the minimum contact length scale such that:

$\mathrm{L}_{\mathrm{COC}}=\min \left(\mathrm{L}_{\mathrm{C}}, \mathrm{L}_{\mathrm{T}}\right)$

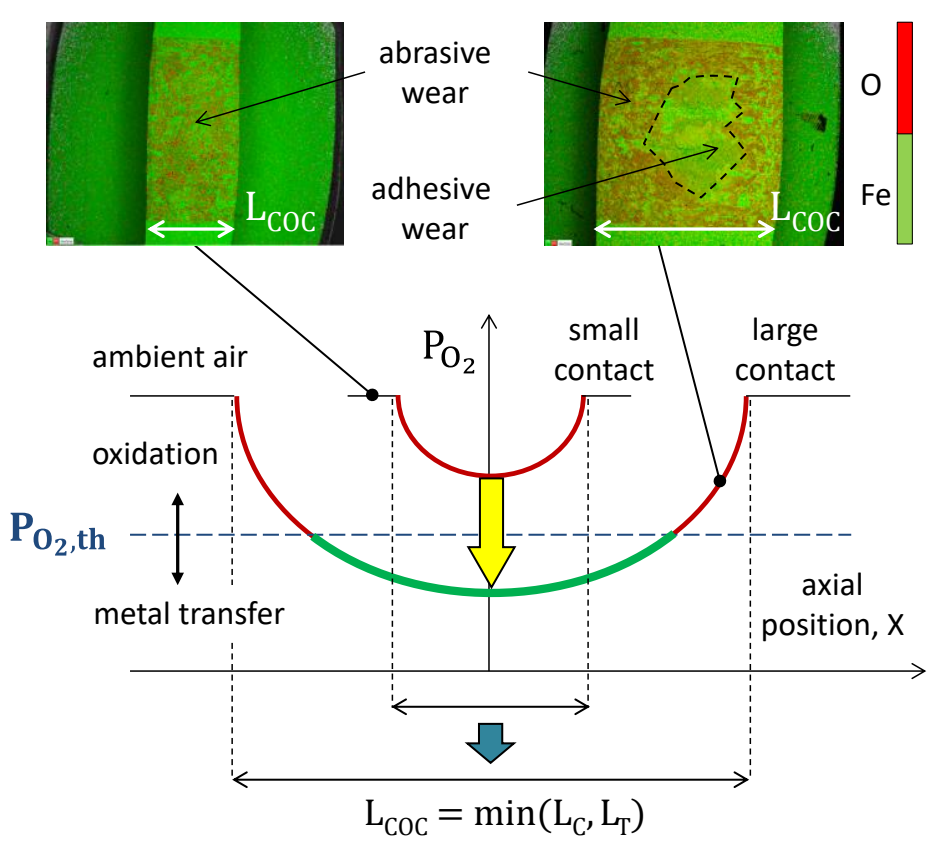

Fig. 13. Illustrating how the contact size extension can promote the formation and the extension of an inner adhesive wear domain although constant iso-friction power density conditions are imposed (After [24]). 


\subsubsection{TBT length scale parameter}

TBT is driven by the debris ejection process so there is a key interest to better examine the debris layer structure generated by $\mathrm{L}_{\mathrm{C}}$ or $\mathrm{L}_{\mathrm{T}}$ contact configuration. Fig. 14 compares the fretted interface of $\mathrm{L}_{\mathrm{T}}=1.25 \mathrm{~mm}(\mathrm{~A})$ and $\mathrm{L}_{\mathrm{C}}=1.25 \mathrm{~mm}(\mathrm{~B})$ experiments at the contact opening. For the same contact area and friction energy dissipation, it is interesting to note that there is more debris at the interface for maximum $\mathrm{L}_{C}=5 \mathrm{~mm}$ condition $(A)$ which also corresponds to a lower wear volume estimated after sample cleaning. Hence, the larger the $\mathrm{L}_{\mathrm{C}}$, the thicker the debris bed and finally the lower the wear rate. This is confirmed by the EDX mapping (Fig. 15 a \& b) which clearly underlines a larger

quantity of oxide debris on the fretting scar compared to the $B$ condition where the $\mathrm{L}_{C}$ contact length is minimized. 


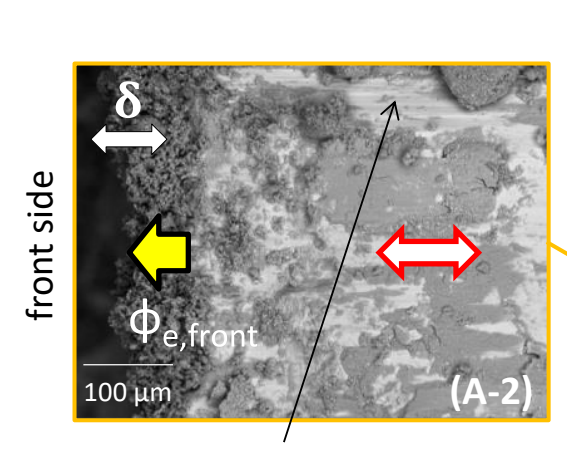

collinear abrasion grooves

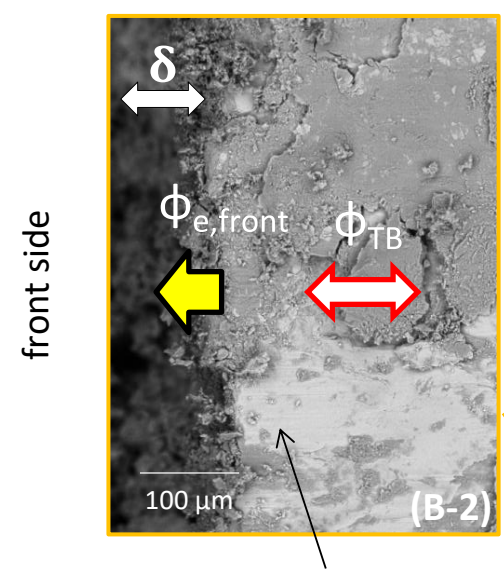

collinear abrasion grooves
$A\left(L_{T}=1.25 \mathrm{~mm} ; L_{C}=5 \mathrm{~mm}\right)$

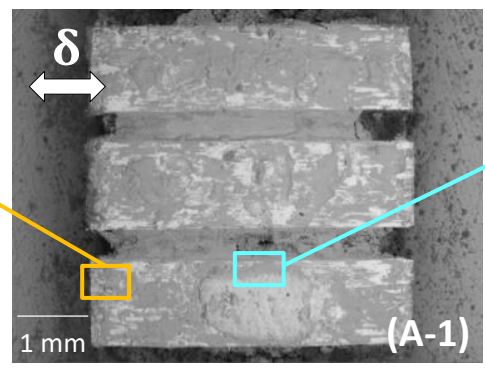

$B\left(\mathrm{~L}_{\mathrm{T}}=5 \mathrm{~mm} ; \mathrm{L}_{\mathrm{C}}=1.25 \mathrm{~mm}\right)$ lateral side

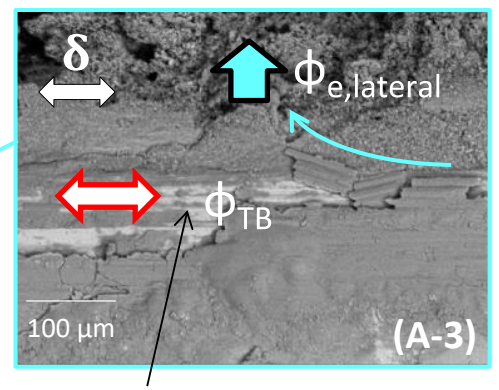

collinear abrasion grooves

lateral side

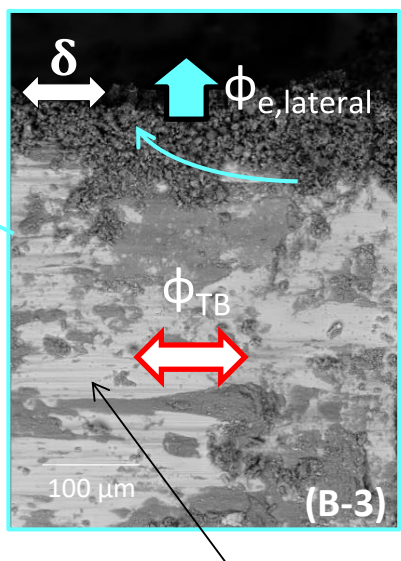

collinear abrasion grooves

Fig. 14. SEM observation before surface cleaning of the textured fretting scars of the bottom samples $A\left(L_{T}=1.25 \mathrm{~mm} ; L_{C}=5 \mathrm{~mm}\right)$ having a wear volume $V=0.384 \mathrm{~mm}^{3}$ then $B\left(L_{T}=5 \mathrm{~mm}\right.$; $\left.\mathrm{L}_{\mathrm{C}}=1.25 \mathrm{~mm}\right)$ having a wear volume $\mathrm{V}=0.727 \mathrm{~mm}^{3}\left(\mathrm{~N}=20000\right.$ cycles, $\mathrm{p}=100 \mathrm{MPa}, \delta_{g}= \pm 0.1 \mathrm{~mm}$ and $\mathrm{f}=1 \mathrm{~Hz}$ ).

This investigation is generalized for all $\mathrm{L}_{\mathrm{T}}$ and $\mathrm{L}_{\mathrm{C}}$ experiments. It is remarkable to note that reducing $\mathrm{L}_{\mathrm{T}}$, the $[\mathrm{O}] /[\mathrm{Fe}]$ ratio (i.e. oxide debris layer presence) remains nearly constant which suggests that the varying $\mathrm{L}_{\mathrm{T}}$ does not influence the third body flow rate. Alternatively, reducing $\mathrm{L}_{\mathrm{C}}$, a continuous reduction of the $[\mathrm{O}] /[\mathrm{Fe}]$ is observed. This indicates that the $\mathrm{L}_{\mathrm{C}}$ length scale parameter could be considered as a pertinent variable to describe the TBT wear rate contribution. 


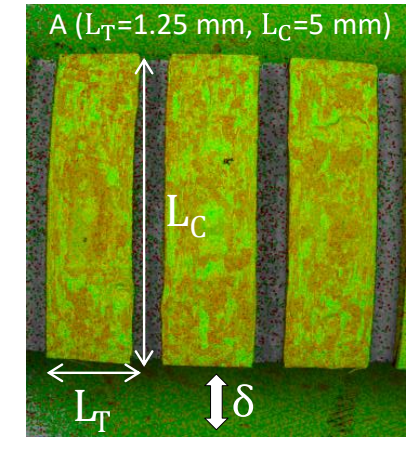

(c)

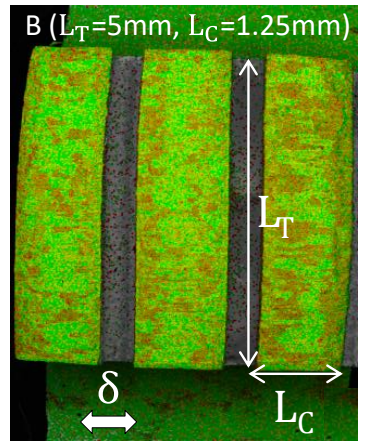

(b)

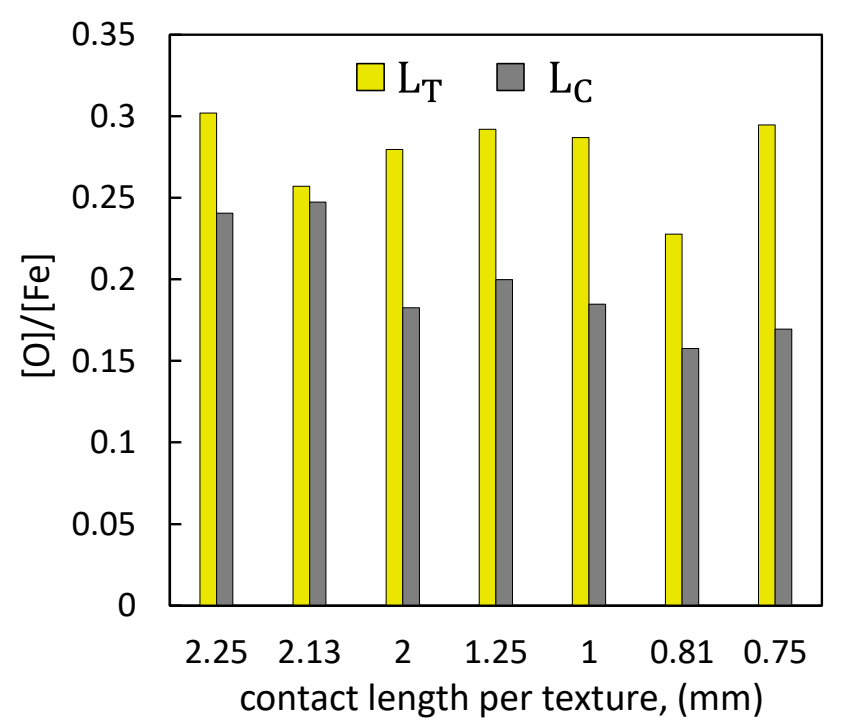

Fig. 15. Comparison of the EDX maps (a): $A\left(L_{T}=1.25 \mathrm{~mm} ; \mathrm{L}_{C}=5 \mathrm{~mm}\right.$ ) fretting scar; (b) $B\left(\mathrm{~L}_{T}=\right.$ $5 \mathrm{~mm} ; \mathrm{L}_{\mathrm{C}}=1.25 \mathrm{~mm}$ ) fretting scar; (c) Oxygen to Iron ratio "[O]/[Fe]" of the bottom textured samples for both orientations with variable $\mathrm{L}_{\mathrm{T}}$ and $\mathrm{L}_{\mathrm{C}}$ (after cleaning with ethanol) as a function of the contact size per textures $\left(\mathrm{N}=20000\right.$ cycles, $p=100 \mathrm{MPa}, \delta_{g}= \pm 0.1 \mathrm{~mm}$ and $\left.\mathrm{f}=1 \mathrm{~Hz}\right)$.

Such conclusion is backed by careful observation of the fretting scars where microabrasion grooves are detected on the first body. These latter are in fact generated by the relative sliding of the hard oxide debris entrapped within the interface before ejection. Whatever the contact configuration, these micro-grooves are systematically collinear to the sliding direction. No transverse micro-grooves can be observed. This suggests that the overall internal third body flow $\phi_{\mathrm{TB}}$ is mainly driven by the collinear 
contribution $\phi_{\mathrm{TB}, \text { collinear }}$ such that the internal transverse flow $\left(\phi_{\mathrm{TB}, \text { transverse }}\right)$ can be neglected.

$\phi_{\mathrm{TB}}=\phi_{\mathrm{TB}, \text { collinear }}+\phi_{\mathrm{TB}, \text { transverse }}$

$\phi_{\mathrm{TB}, \text { transverse }}=0 \Rightarrow \phi_{\mathrm{TB}}=\phi_{\mathrm{TB}, \text { collinear }}$

Concerning the external ejection flow, two front and lateral components (i.e. $\phi_{e, l a t e r a l}$ and $\left.\phi_{\mathrm{e}, \text { front }}\right)$ can be distinguished. The front debris flow $\phi_{\mathrm{e}, \text { front }}$ can be related to the collinear internal debris flow (i.e. $\phi_{\mathrm{TB}, \text { collinear }}$ ). However, the lateral ejection flow is more questionable. Since no transverse micro-abrasion grooves are observed, it can be assumed that $\phi_{\mathrm{e}, \text { lateral }}$ component is in fact coming from a part of $\phi_{\mathrm{TB}, \text { collinear }}$ assuming that, due to the high hydrostatic pressure within the debris layer, some of the debris particles located next to the lateral edges are expelled to the lateral borders. This can be confirmed by the twist motion of debris platelets noticed on the lateral side Fig. 14 $(A-3)$.

$\phi_{\mathrm{TB}}=\phi_{\mathrm{TB}, \text { collinear }}=\phi_{\mathrm{e}, \text { front }}+\phi_{\mathrm{e}, \text { lateral }}$

Most of the surface observations reveal a larger $\phi_{\mathrm{e}, \text { front }}$ contribution compared to the lateral one (Fig. $12 \&$ 14). Besides, the given friction energy wear formalism implies considering the dissipation sites and therefore considering rather the internal debris flow as a representative of the TBT wear process. Since this latter is exclusively controlled by a collinear contribution, it can be assumed that the pertinent contact length scale controlling the third body ejection process is the collinear length scale such that:

$\mathrm{L}_{\mathrm{TBT}}=\mathrm{L}_{\mathrm{C}}$ 
To better interpret the TBT wear rate evolution, it appears interesting to apply Fillot et al. [18] model successively "translated" in terms of "debris flow-debris layer thickness" chart by Arnaud et al. in [33] (Fig. 16). As expected, the debris ejection flow increases with the third body thickness due to the larger debris ejection volume expelled from the contact during each fretting cycle (Fig. 16). Alternatively, the debris formation flow from the first bodies tends to decrease due to a higher protective action of the thicker third body layer. Hence, the steady state wear flow is reached when the debris formation flow equals the debris ejection one.

$\phi_{\mathrm{W}}=\phi_{\mathrm{e}}=\phi_{\mathrm{f}}$

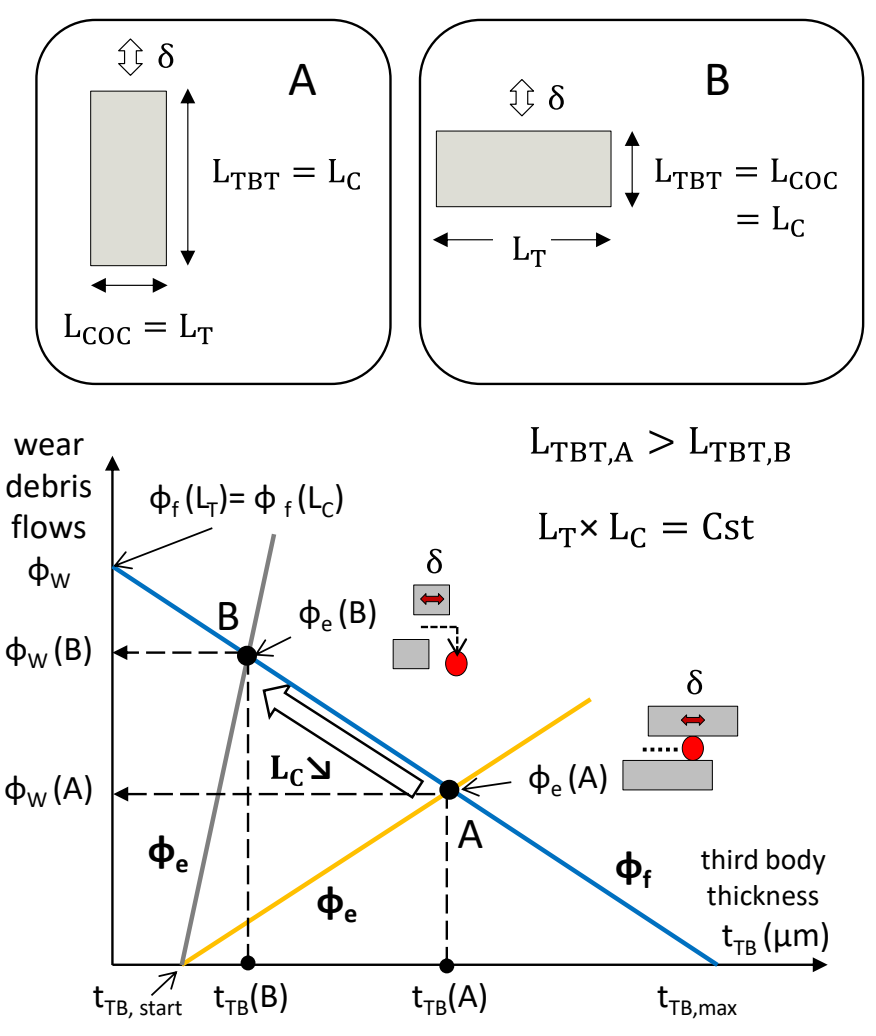

Fig. 16. Application of the debris flows - third body thickness chart to interpret the effect of $\mathrm{L}_{C}$ fluctuation regarding the third body layer. Assuming iso-contact size so that $\mathrm{L}_{\mathrm{T}} \times \mathrm{L}_{\mathrm{C}}=$ constant, a 
reduction of $\mathrm{L}_{\mathrm{C}}$ increases the debris ejection flow and consequently reduces the third body thickness and increases the wear flow.

This steady state condition also corresponds to a stabilized third body thickness $\left(\phi_{\mathrm{TB}}\right)$. Since the contact oxygenation and the friction work are nearly the same whatever the contact orientation for the same contact area, the initial debris formation flows are assumed similar (i.e. $\phi_{\mathrm{f}}\left(\mathrm{L}_{\mathrm{T}}\right)=\phi_{\mathrm{f}}\left(\mathrm{L}_{\mathrm{C}}\right)$ ). Therefore, as discussed previously, by decreasing $L_{C}$ the presence of debris in the interface will be shortened so that the thickness of the debris bed will be reduced. The protection of the first bodies will be reduced which in turn will promote an increase in the debris formation rate and a rising of the global wear rate. This wear rate dependency versus third body thickness is also fully consistent with the former EDX $[\mathrm{O}] /[\mathrm{Fe}]$ ratio investigation (Fig. 15): the faster the debris ejection process, the thinner the debris layer entrapped within the interface and the lower the $[\mathrm{O}] /[\mathrm{Fe}]$ ratio.

\subsubsection{Relative influence of $\mathrm{COC}$ and TBT contributions on wear rate fluctuations}

By considering $\mathrm{L}_{\mathrm{TBT}}$ and $\mathrm{L}_{\mathrm{COC}}$ length scale parameters, the evolution of $\mathrm{L}_{\mathrm{C}}$ and $\mathrm{L}_{\mathrm{T}}$ wear rates detailed in Fig. 11 can be more easily interpreted. Indeed, for $\mathrm{L}_{\mathrm{T}}$ experiments (yellow markers) the collinear length scale is constant which implies that a similar third body internal flow operates. However, by decreasing $\mathrm{L}_{T}$, the contact oxygenation increases, promoting thicker oxide layer on the fretted interface which in turn increases the debris formation rate but also the ejection process such that the powdery oxide particles are more easily ejected. Hence, by favouring the tribo-oxidation processes, a decrease of $\mathrm{L}_{T}$ increases the energy wear rate. Regarding $\mathrm{L}_{C}$ experiments (grey markers), a decrease of $\mathrm{L}_{\mathrm{C}}$ simultaneously affects the TBT debris ejection but also the 
contact oxygenation. This can explain the higher wear rate observed for $\mathrm{L}_{C}$ experiments compared to $\mathrm{L}_{\mathrm{T}}$ ones. This combined $\mathrm{L}_{\mathrm{T}}$ and $\mathrm{L}_{\mathrm{C}}$ wear rate analysis appears as a pertinent strategy to decouple the relative influence of COC and TBT contributions. This tendency is better quantified by introducing the following $\mathrm{COC}$ and TBT wear rate fluctuation parameters such that:

$\Delta \alpha_{\mathrm{COC}}=\alpha_{\mathrm{L}_{\mathrm{T}}}-\alpha_{\mathrm{ref}}$

$\Delta \alpha_{\mathrm{TBT}}=\alpha_{\mathrm{LC}_{\mathrm{C}}}-\alpha_{\mathrm{LT}_{\mathrm{T}}}$

Both $\Delta \alpha_{\mathrm{COC}}$ and $\Delta \alpha_{\mathrm{TBT}}$ are plotted versus $\mathrm{L}_{\mathrm{COC}}$ and $\mathrm{L}_{\mathrm{TBT}}$ respectively in Fig. 17.

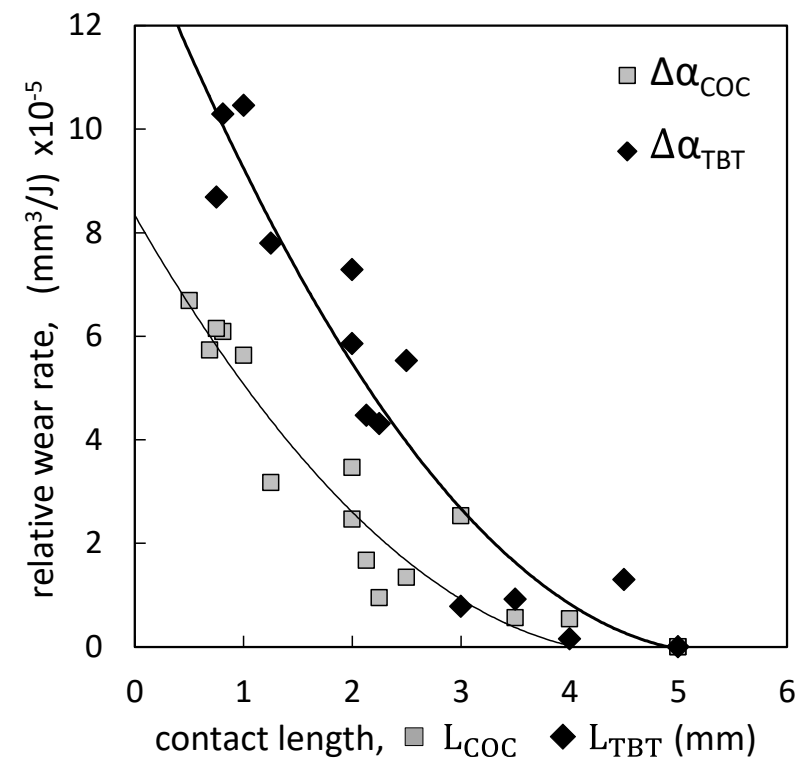

Fig. 17. Evolution of the relative $C O C$ and TBT energy wear rate contribution extracted from the $\mathrm{L}_{\mathrm{C}}$ and $\mathrm{L}_{\mathrm{T}}$ experiments such that $\mathrm{L}_{\mathrm{C}}=5 \mathrm{~mm}$ if $\mathrm{L}_{\mathrm{T}}$ varies and $\mathrm{L}_{\mathrm{T}}=5 \mathrm{~mm}$ if $\mathrm{L}_{\mathrm{C}}$ varies (the other loading parameters are kept constant at the reference condition: $\mathrm{N}=20000$ cycles, $\mathrm{p}=100 \mathrm{MPa}$, $\delta_{g}= \pm 0.1 \mathrm{~mm}$ and $\mathrm{f}=1 \mathrm{~Hz}$ ).

This figure suggests equivalent asymptotic decrease of the wear rate contribution with the related contact lengths. Nevertheless, it appears that the TBT wear rate influence is 
slightly higher than that of COC. This aspect will be better illustrated in the following wear modeling section.

3.4.4 Coupled influence of the sliding amplitude $\delta_{\mathrm{g}}$ with $\mathrm{L}_{\mathrm{TBT}}$ parameter

The role of the sliding amplitude on fretting wear kinetics was previously investigated in [27] for similar flat-on-flat 34NiCrMo16 interface. This former investigation suggests that the sliding amplitude has a negligible impact on the friction coefficient which has a global average value $\mu_{\mathrm{e}}=0.70 \pm 0.04$ (Fig. 10 of [27]). On the other hand, increasing the sliding amplitude tends to increases the energy wear rate as detailed in Fig. 13 of [27]. Since both the contact size along the sliding direction " $\mathrm{L}_{\mathrm{C}}=\mathrm{L}_{\mathrm{TBT}}$ " and the sliding amplitude " $\delta_{\mathrm{g}}$ " display a reverse influence on the debris ejection (i.e. the longer " $\mathrm{L}_{\mathrm{TBT}}$ ", the longer the debris entrapment and the longer " $\delta_{\mathrm{g}}$ " the shorter the debris entrapment), it appears interesting to combine these two variables considering the " $\mathrm{L}_{\mathrm{TBT}} / \delta_{\mathrm{g}}$ " ratio. Fig. 18 confirms that a single wear rate master curve combining both $\delta_{\mathrm{g}}$ and $\mathrm{L}_{\mathrm{TBT}}$ variables can be derived by assuming $\mathrm{L}_{\mathrm{TBT}} / \delta_{\mathrm{g}}$ ratio. Again, an asymptotic decreasing evolution can be observed. 


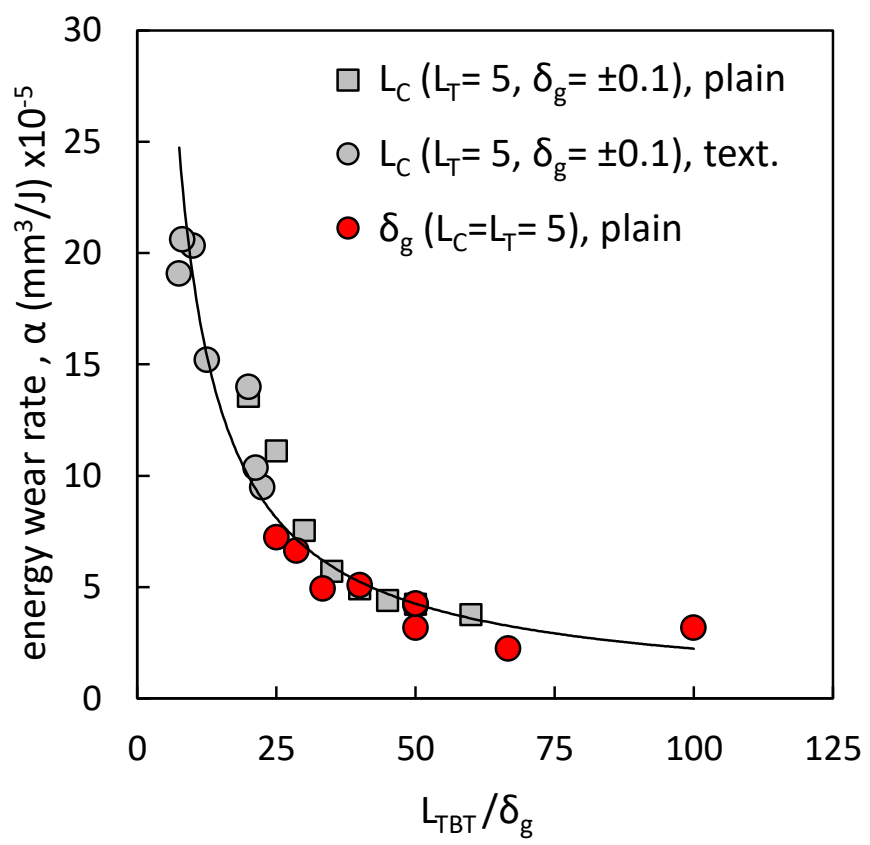

Fig. 18. Evolution of the energy wear rate " $\alpha$ " versus the $\mathrm{N}_{\mathrm{TBT}}=\mathrm{L}_{\mathrm{TBT}} / \delta_{\mathrm{g}}$ ratio for plain and textured samples (Fig. 5b) ( $N=20000$ cycles, $p=100 \mathrm{MPa}, \mathrm{f}=1 \mathrm{~Hz}$, and $\mathrm{L}_{\mathrm{T}}=5 \mathrm{~mm}$ ).

By increasing $\mathrm{L}_{\mathrm{TBT}} / \delta_{\mathrm{g}}$ either by decreasing $\delta_{\mathrm{g}}$ or increasing $\mathrm{L}_{\mathrm{TBT}}$, the elimination of the third body particles will be slower. The increase of the residence time of the debris particles in the interface increases the thickness of the debris bed protecting in turn the first bodies against wear (i.e. reducing the energy wear rate) [9]. This result is quite interesting as it reflects that the energy wear rate is inversely proportional to the number of the sliding steps required to eliminate the wear debris from the interface such that:

$\mathrm{N}_{\mathrm{TBT}}=\mathrm{L}_{\mathrm{TBT}} / \delta_{\mathrm{g}}$

In other words, the longer the debris path $\left(\mathrm{L}_{\mathrm{TBT}}\right)$ and the smaller the sliding amplitude $\left(\delta_{\mathrm{g}}\right)$, the higher is the number of cycles $\left(\mathrm{N}_{\mathrm{TBT}}\right)$ required to eliminate the wear debris from the interface. Note that such asymptotic decrease converges toward a constant value above a threshold $\mathrm{N}_{\mathrm{TBT} \text {,th }}$ value estimated to be around 60 for the studied condition. 
3.4.5 Modeling contact size effect on wear rate fluctuations and wear volume extension

Various strategies were considered in the past decades to simulate the asymptotic decrease of the wear rate versus the contact size. A first approach based on a power law formulation was introduced in [21] then extended in [22] such that:

$\alpha=\alpha_{\text {ref }} \times\left(\frac{\mathrm{L}_{\mathrm{ref}}}{\mathrm{L}}\right)^{\mathrm{n}_{\mathrm{L}}}$

where $L$ is a contact length scale representative of the contact size effect, $L_{r e f}$ is a reference contact size condition and $\mathrm{n}_{\mathrm{L}}$ is the exponent monitoring the $\mathrm{L}$ contact length scale influence on the fretting wear rate fluctuation. These first works were undertaken for non-conformal Hertzian sphere-on-flat and cylinder-on-flat steel interfaces. The authors, by associating the variable $\mathrm{L}$ to the Hertzian contact radius (i.e. $\mathrm{L}=\mathrm{a}_{\mathrm{H}}$ ) found a rather nice correlation with experiments assuming $n_{L}=0.9$ (Fig. 1). The authors underlined that the longer the debris path within the interface, the smaller the debris ejection flow rate and consequently the lower the wear rate. This explanation can be related to the given $\mathrm{N}_{\text {TBT }}$ sliding steps required to eliminate the wear debris from the interface.

This approach was extended by Zhu et al. $[9,10]$ considering a dynamical evolution of the wear volume extension where the contact size effect is assumed inversely proportional to the sliding path:

$$
\frac{\mathrm{dV}}{\mathrm{dEd}}=\frac{\mathrm{k}}{\mathrm{L}}
$$


This formulation is in fact equivalent to the given wear rate description (Eq. 17) considering a steady state linear wear volume extension versus the friction work dissipated in the interface if $\mathrm{n}_{\mathrm{X}}$ is approximated to 1 and $\mathrm{k}=\alpha_{\mathrm{ref}} \times \mathrm{L}_{\mathrm{ref}}$ (Eq. 19).

$\frac{\mathrm{dV}}{\mathrm{dEd}}=\frac{\mathrm{V}}{\Sigma \mathrm{Ed}}=\alpha=\alpha_{\mathrm{ref}} \times\left(\frac{\mathrm{L}_{\mathrm{ref}}}{\mathrm{L}}\right)^{\mathrm{n}_{\mathrm{L}}}=\frac{\mathrm{k}}{\mathrm{L}}$

In this investigation, a coupled effect of TBT and COC processes is underlined through $\mathrm{L}_{\mathrm{COC}}$ and $\mathrm{L}_{\mathrm{TBT}}$ length scales. Therefore, an equivalent power law formalism previously introduced in [27] is adopted here to capture the contact size effect:

$\alpha_{\mathrm{L}, \delta}=\alpha_{\mathrm{ref}} \times\left[\frac{\mathrm{L}_{\mathrm{LOC}}}{\mathrm{L}_{\mathrm{COC}, \mathrm{ref}}}\right]^{\mathrm{n}_{\mathrm{COC}}} \times\left[\frac{\mathrm{L}_{\mathrm{TBT}} / \delta_{\mathrm{g}}}{\mathrm{L}_{\mathrm{TBT}, \mathrm{ref}} / \delta_{\mathrm{g}, \mathrm{ref}}}\right]^{\mathrm{n}_{\mathrm{TBT}}}$

with $\mathrm{L}_{\mathrm{COC}, \text { ref }}=\mathrm{L}_{\mathrm{TBT}, \text { ref }}=\mathrm{L}_{\mathrm{ref}}=5 \mathrm{~mm}, \delta_{\mathrm{g}, \mathrm{ref}}=0.1 \mathrm{~mm}$ and $\alpha_{\mathrm{ref}}=4.23 \times 10^{-5} \mathrm{~mm}^{3} / \mathrm{J}$.

In this formulation the effective TBT wear rate contribution expressed through $\left(\mathrm{L}_{\mathrm{TBT}} / \delta_{\mathrm{g}}\right)^{n_{T B T}}$ term is weighted by the $\mathrm{COC}$ process through $\left(\mathrm{L}_{\mathrm{COC}}\right)^{n_{C O C}}$ parameter. $\mathrm{A}$ numerical fitting analysis is performed using the experimental results compiled in Fig. 11 and 18 (i.e. test procedure Fig. 5) which leads to $\mathrm{n}_{\mathrm{COC}}=-0.4$ and $\mathrm{n}_{\mathrm{TBT}}=-0.6$. A very nice correlation versus the experimental wear rate confirms the stability of this proposal (Fig. 19). 


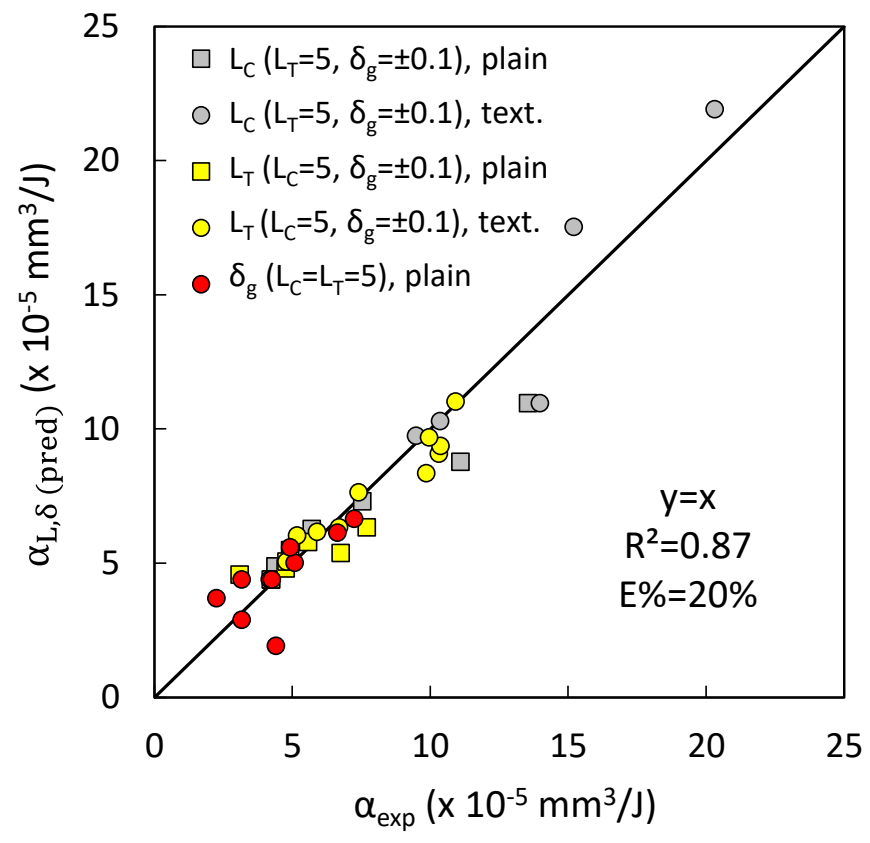

Fig. 19. Comparison between the experimental and the predicted wear rate (Eq. 20) varying $\mathrm{L}_{C}$, $\mathrm{L}_{\mathrm{T}}$ and $\delta_{\mathrm{g}}$ while keeping the other loading parameters constant at $\mathrm{N}=20000$ cycles, $\mathrm{p}=100 \mathrm{MPa}$, $f=1 \mathrm{~Hz} \delta_{g}= \pm 0.1 \mathrm{~mm}$ for $L_{C}$ and $L_{T}$ experiments.

It is interesting to note that $n_{\text {COC }}$ influence is at least $30 \%$ lower than the $n_{\text {TBT }}$ which indirectly confirms the former $\Delta \alpha_{\mathrm{COC}}$ and $\Delta \alpha_{\mathrm{TBT}}$ analysis indicating that TBT displays a higher wear rate influence than COC. Besides, when $\mathrm{L}_{\mathrm{COC}}=\mathrm{L}_{\mathrm{TBT}}=\mathrm{L}$, as observed for sphere-on-flat or cylinder-on-flat contacts, and assuming constant sliding amplitudes, the former expression can be simplified to:

$\alpha_{\mathrm{L}, \delta}=\alpha_{\mathrm{ref}} \times\left[\frac{\mathrm{L}_{\mathrm{ref}}}{\mathrm{L}}\right]$

which corresponds to former formulations derived by Merhej et al. [21,22] and Zhu et al. $[9,10]$. This confirms that for these non-conformal contacts, the wear rate is inversely proportional to the collinear contact length (i.e. contact radius for sphere-on-flat and cylinder-on-flat). One interest of the given formulation (Eq. 20) is the possibility to 
distinguish the relative influence of TBT and $\mathrm{COC}$ processes on the wear rate fluctuation induced by the contact size and the sliding amplitude. To confirm the stability of this approach, the model was applied for various loading conditions comparing the experimental and predicted wear volume (Fig. 20) given by:

$\mathrm{V}_{\text {pred }}=\alpha_{\mathrm{L}, \delta} \times \sum \mathrm{Ed}$

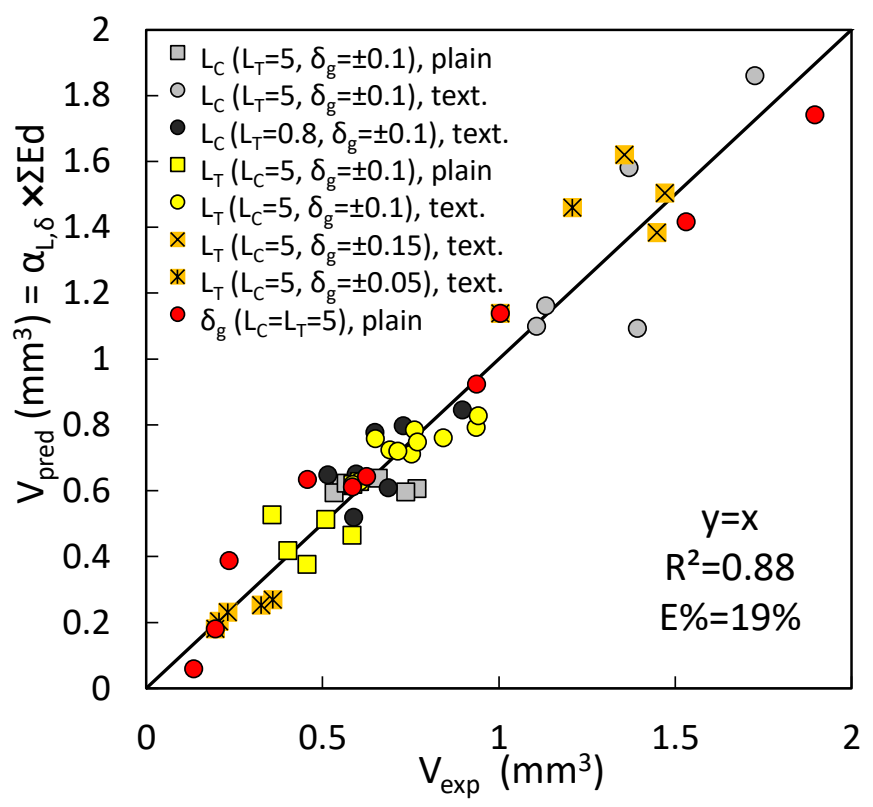

Fig. 20. Comparison between the experimental and predicted wear volumes (Eq. 22) by varying the contact size parameters $\mathrm{L}_{\mathrm{C}}(\mathrm{mm}), \mathrm{L}_{\mathrm{T}}(\mathrm{mm})$ and the sliding amplitude $\delta_{\mathrm{g}}( \pm \mathrm{mm})$ but keeping the other loading parameter constant where $\mathrm{N}=20000$ cycles, $\mathrm{p}=100 \mathrm{MPa}$, and $\mathrm{f}=1 \mathrm{~Hz}$.

The standard deviation error expressed by Eq. 23 remains lower than 19\% whereas the coefficient of determination $R^{2}$ reaches 0.88 . This very good correlation with experiments validates the stability of the proposed model.

$\mathrm{E} \%=100 \times \sqrt{\frac{\sum_{\mathrm{i}=1}^{\mathrm{n}}\left(\frac{\mathrm{V}_{\text {pred }}-\mathrm{V}_{\text {exp }}}{\mathrm{V}_{\exp }}\right)^{2}}{\mathrm{n}}}$ 


\section{Discussion}

Results show that an increase of the collinear $\mathrm{L}_{\mathrm{C}}$ and the transverse $\mathrm{L}_{\mathrm{T}}$ contact sizes decreases asymptotically the wear rate but in a different way. To interpret such complex transitions and the related wear rate evolution, both the contact oxygenation concept (COC) and the third body approach (TBT) were discussed and formalized considering $\mathrm{L}_{\mathrm{COC}}=\min \left(\mathrm{L}_{\mathrm{C}}, \mathrm{L}_{\mathrm{T}}\right)$ and $\mathrm{L}_{\mathrm{TBT}}=\mathrm{L}_{\mathrm{C}}$ contact length scale parameters. Finally, by introducing a power law approach taking into account both COC and TBT contributions, a simple formulation of the energy wear rate function versus the contact size and the sliding amplitude is derived. The very good correlation with numerous experiments performed using different contact configurations approves the stability of the proposal. It was also shown that for more conventional contact configuration like sphere-on-flat or cylinder-on-flat contacts, when $\mathrm{L}_{\mathrm{COC}}=\mathrm{L}_{\mathrm{TBT}}$ the given model predicts well the $1 / \mathrm{L}$ contact size dependency previously detailed in literature $[9,10,21,22]$. The very good prediction of the experimental wear volumes also indirectly supports the hypothesis of a linear steady state wear volume extension at least for the studied conditions. This power law modeling $[9,21]$ expressing the wear rate as an inverse function of the characteristic contact size (i.e. $\alpha \propto 1 / \mathrm{L}^{\mathrm{n}_{\mathrm{L}}}$ ) infers mathematically that the wear rate converges to an infinite value when the contact size converges to zero whereas it converges to zero when the contact size converges to infinity. This aspect was discussed in [9] stating that an infinite contact size implies an infinite debris path hence an infinite entrapment of the debris within the interface and therefore no-wear response. Alternatively, it can be also argued that an infinite contact size does not imply any open edges allowing the debris ejection process which is, in an equivalent way, suggests that the wear rate converges 
to zero. An essential question, however, concerns the representativeness of an infinite contact hypothesis to describe the wear kinetics of very large industrial contacts which physically display free edges allowing the debris ejection process and therefore a nonzero wear rate. Indeed, various experimental investigations [20] suggest that a better description of the contact size wear rate fluctuation is achieved assuming a very low but non-zero residual wear rate for very large contact configurations. An open question would be to check if this residual wear rate is constant involving an alternative threshold power law formulation as that introduced in [21] or, as discussed in [9], this residual wear rate may be related to an asymptotic decreasing value with the contact size. To clarify this aspect further development will be undertaken to investigate very large contact size response. Note that a similar experimental strategy focusing on very small contact sizes would be interesting to evaluate the stability of the proposed power law formalism which is up to now mainly established for micro-meso contacts sizes.

Another surprising aspect concerns the continuous evolution of the wear rate (Fig. 11) at the transition from pure abrasive to composite abrasive/adhesive wear behavior. This transition should be reflected in a discontinuous evolution which is not observed in the current study. The continuous evolution of $\mathrm{L}_{\mathrm{T}}$ experiments may be explained by the fact that even if the entire interface is sufficiently oxygenated to switch to abrasive wear, the smaller the $\mathrm{L}_{\mathrm{COC}}$, the higher the interfacial oxygen partial pressure, the thicker the oxide layer formed and finally the higher the wear rate as demonstrated by the tribooxidation wear models $[34,35]$. However, more in-depth studies will be developed to clarify and confirm this point. 
Another key aspect concerns the steady state hypothesis. Many aspects (i.e. stability of the friction coefficient and the linear wear volume evolution) suggest that the fretting wear evolution is stable at the studied 20000 fretting cycles. However, the steady state response in tribology must be considered as a relative concept. One can assume that the interface evolves in very long test situations inducing, for instance, a progressive elimination of the inner adhesive zone $[9,36]$. To investigate this aspect, a fretting test performed at the reference loading condition was extended up to 50000 fretting cycles. The comparison of EDX fretting scars confirms a stable evolution of the partition between inner adhesive wear and external abrasive wear domains (Fig. 21). This indirectly suggests that the given 20000 cycles test duration captures well the steady state wear response of the studied interface in terms of friction, wear kinetics but also wear mechanisms.

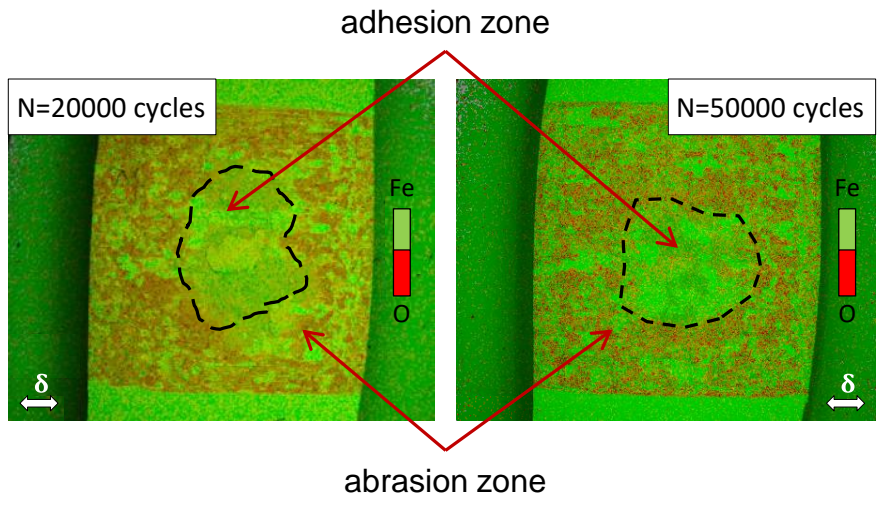

Fig. 21. Comparison between the EDX maps of the fretting scars obtained after 20000 and 50000 fretting cycles $\left(\mathrm{L}_{\mathrm{T}}=\mathrm{L}_{\mathrm{C}}=5 \mathrm{~mm}, \mathrm{p}=100 \mathrm{MPa}, \delta_{\mathrm{g}}= \pm 0.1 \mathrm{~mm}\right.$, and $\left.\mathrm{f}=1 \mathrm{~Hz}\right)$.

This stable evolution of the composite adhesive/abrasive fretting scar can be interpreted considering recent multiphysics simulations coupling $\mathrm{COC}$ and surface wear modeling including third body layer [26]. This research work predicts a stable area of the inner 
adhesion domain even after a large number of fretting cycles due to contact pressure discontinuity at the boundary between adhesive and abrasive wear zones blocking the oxygen diffusion within the inner part of the contact. Future experimental work will be undertaken to clarify this aspect for very long test up to $10^{6}$ cycles.

Regarding the given wear rate modeling, one hypothesis is that COC is fully isotropic whereas TBT is anisotropic. However, these first approximations must be tempered. For instance, it can be supposed that collinear debris flow and large sliding amplitudes have an effect on the oxygen diffusion within the debris bed. Therefore, an anisotropic description of COC process could be considered in the future to better describe the contact size and the sliding amplitude effects. The given results propose, however, a very weak contribution of the studied sliding amplitude on COC, yet some fluctuations are expected for larger sliding amplitude. The best fitting analysis in [27] suggested $\mathrm{n}_{\delta \mathrm{g}}=0.7$ which can be related to the TBT component (i.e. $\mathrm{n}_{\mathrm{TBT}}=0.6$ ) plus a residual influence of other damage processes (i.e. $\mathrm{n}_{\delta_{\text {res }}}=0.1$ ). Most of the sliding amplitude influence appears related to the debris ejection process, however another part could be linked to other damage processes like tribo-oxidation as suggested by Dreano et al. in [35] and/or the COC process. Hence, a complementary experimental work needs to be undertaken to better isolate the effect of $\delta_{\mathrm{g}}$ regarding TBT but above all COC and tribooxidation phenomena.

Regarding the TBT description, only the collinear internal debris flow parameter is addressed assuming $\mathrm{L}_{\mathrm{TBT}}=\mathrm{L}_{\mathrm{C}}$. However, a lateral debris ejection component needs to be carefully examined in future using a dedicated experimental work. Perhaps the given 
macro-textured interface strategy is not so relevant to isolate this aspect. Hence, mesomacro-contact configuration allowing the investigation of very narrow $\mathrm{L}_{\mathrm{T}}$ length appears as an alternative to deepen this analysis.

To conclude, one of the interesting aspects of this approach is its capacity to decouple both $\mathrm{COC}$ and TBT contributions with respect to the global wear rate. Besides, it is possible to include the effect of other loading parameters introduced in details in [27]. For instance, after [27] the contact pressure effect can be formalized using a power expression such that:

$\alpha_{p}=\alpha_{\text {ref }} \times\left(\frac{p}{p_{\text {ref }}}\right)^{0.6}$

The physical interpretation of this positive 0.6 exponent is still unclear. After $\mathrm{COC}$, the higher the contact pressure, the larger the extension of the inner adhesive wear domain and therefore the lower the wear rate. Alternatively after the TBT, an increase of the contact pressure tends to raise the hydrostatic pressure imposed within the third-body layer, which in turn favors the debris ejection process. Hence, the higher the contact pressure the thinner the debris layer and therefore the higher the wear rate. Another interpretation can be related to the plastic response of the material as described by the K.L. Johnson chart displaying [37] the different domains of elastic, elastic shakedown and plastic ratchetting responses as a function of the coefficient of friction and the maximum contact pressure. Therefore, the higher the contact pressure the larger the plastic deformation and therefore the higher the wear rate [38].

Regarding the sliding frequency effect, former investigations [27] underlined an asymptotic decrease of the energy wear rate so that: 
$\alpha_{\mathrm{f}}=\alpha_{\text {ref }} \times\left(\frac{\mathrm{f}}{\mathrm{f}_{\mathrm{ref}}}\right)^{-0.35}$

with $\alpha_{\text {ref }}=4.23 \times 10^{-5} \mathrm{~mm}^{3} / \mathrm{J}$ and $\mathrm{f}_{\text {ref }}=1 \mathrm{~Hz}$.

As discussed previously, the effect of the sliding frequency can be addressed through a tribo-oxidation approach. Dreano et al. [35] suggested that the fretting wear rate can be related to the oxide thickness formed on the fresh metal between each sliding period. Hence, the higher the sliding frequency, the thinner the oxide layer and the lower the wear rate. This approach of the metal oxidation, based on the Arrhenius law, shows that the thickness of the oxide film formed between each sliding sequence is inversely proportional to the square root of the frequency. Assuming that the abrasive wear rate is proportional to the thickness of the oxide layer (i.e. a fraction of the thickness of oxide removed by the mechanical action of the sliding contact), we can deduce that the wear kinetics is also inversely proportional to the square root of the frequency so that $\alpha \propto \mathrm{f}^{-0.5}$. This simple tribo-oxidation approach can clarify the observed reduction of the wear rate with the increase of frequency $\left(\alpha \propto \mathrm{f}^{-0.35}\right)$. The slight difference between the exponents can be explained by the occurrence of adhesive zone and the potential interactions with third body flow.

The power law approach developed in [27] is considered here to combine all loading parameters. The wear volume prediction assuming a steady state wear rate response is expressed by:

$\mathrm{V}_{\text {pred }}=\alpha^{*} \times \sum \mathrm{Ed}$

With $\alpha^{*}$ being the extended energy wear rate. 
This extended energy wear rate is approximated by a factorial function of the power law components:

$$
\alpha^{*}=\alpha_{\text {pref }} \times \prod\left(\frac{\mathrm{x}}{\mathrm{x}_{\mathrm{ref}}}\right)^{\mathrm{n}_{\mathrm{x}}}
$$

The contact loading parameter $\mathrm{X}$ can be substituted by $\mathrm{L}_{\mathrm{COC}}, \mathrm{L}_{\mathrm{TBT}}, \delta_{\mathrm{g}}, \mathrm{p}$ and $\mathrm{f}$ respectively. Neglecting the residual contribution of the sliding amplitude (i.e. stating that $\mathrm{n}_{\delta_{\mathrm{res}}}=0$ ), the explicit formulation related to the studied flat-on-flat interface can be derived by combining Eqs. 20, 24, 25 and 26 leading to:

$\alpha^{*}=\alpha_{\text {ref }} \times\left[\frac{\mathrm{L}_{\text {COC }}}{\mathrm{L}_{\mathrm{COC}, \text { ref }}}\right]^{\mathrm{n}_{\mathrm{COC}}} \times\left[\frac{\mathrm{L}_{\mathrm{TBT}} / \delta_{\mathrm{g}}}{\mathrm{L}_{\mathrm{TBT}, \text { ref }} / \delta_{\mathrm{g}, \text { ref }}}\right]^{\mathrm{n}_{\mathrm{TBT}}} \times\left[\frac{\mathrm{p}}{\mathrm{p}_{\text {ref }}}\right]^{\mathrm{n}_{\mathrm{p}}} \times\left[\frac{\mathrm{f}}{\mathrm{r}_{\mathrm{ref}}}\right]^{\eta_{\mathrm{f}}}$

where $\alpha_{\text {ref }}=4.23 \times 10^{-5} \mathrm{~mm}^{3} / \mathrm{J}, \mathrm{n}_{\mathrm{COC}}=-0.4, \mathrm{n}_{\mathrm{TBT}}=-0.6, \mathrm{n}_{\mathrm{p}}=0.6, \mathrm{n}_{\mathrm{f}}=-0.35$.

Note that for the specific cases where $\mathrm{L}_{\mathrm{COC}}=\mathrm{L}_{\mathrm{TBT}}=\mathrm{L}$ like observed for non-conformal sphere-on-flat or cylinder-on-flat contacts, the former expression can be simplified to:

$\alpha^{*}=\alpha_{\text {ref }} \times\left[\frac{\mathrm{L}}{\mathrm{L}_{\text {ref }}}\right]^{-1} \times\left[\frac{\delta_{\mathrm{g}}}{\delta_{\mathrm{g}, \mathrm{ref}}}\right]^{0.6} \times\left[\frac{\mathrm{p}}{\mathrm{p}_{\text {ref }}}\right]^{0.6} \times\left[\frac{\mathrm{f}}{\mathrm{f}_{\text {ref }}}\right]^{-0.35}$

which indirectly allows us to justify the $1 / \mathrm{L}$ formulations derived in [21] and [9].

This extended wear rate formulation (Eq. 28) is in fact very similar to a previous expression developed in [39] (Eq. 3.8) except that in this latter work the $\mathrm{L}_{\mathrm{TBT}}$ length is directly related to $\mathrm{L}_{\mathrm{C}}$ whereas the $\mathrm{L}_{\mathrm{COC}}$ length scale parameter is approximated by the $\mathrm{L}_{\mathrm{T}}$ transverse contact length. The difference is very small such that most of the $\mathrm{L}_{\mathrm{COC}}=$ $\min \left(\mathrm{L}_{\mathrm{C}}, \mathrm{L}_{\mathrm{T}}\right)$ values are in fact equal to $\mathrm{L}_{\mathrm{T}}$. However, one interest of the given 
formulation is that both $\mathrm{COC}$ and TBT are more clearly explicit using $\mathrm{L}_{\mathrm{COC}}$ and $\mathrm{L}_{\mathrm{TBT}}$ length scale parameters. Besides, the given approach (Eq. 20, 28) suggests that the wear rate is proportional to the product of a function related to that contact oxygenation and a function related to the third-body theory. This is in direct contrast to a recent proposal introduced by Shipway et al. [36] suggesting that the wear rate will be the rate of the slowest process which controls wear (i.e. the concept of the rate determining process). It appears here a very interesting scientific challenge to compare these two approaches to better understand the effect of the contact size with respect to the wear rate fluctuations.

Fig. 22 compares the experimental and predicted wear volume derived from this extended friction energy wear rate expression (Eq. 28). Again very good correlations with experiments confirm the stability of this approach. Despite its simplicity, this model allows to take into account the effect of the contact size and the sliding amplitude through a synergic COC and TBT analysis, the effect of the contact pressure considering local plasticity at the asperity scale and the effect of frequency considering a tribo-oxidation contribution. 


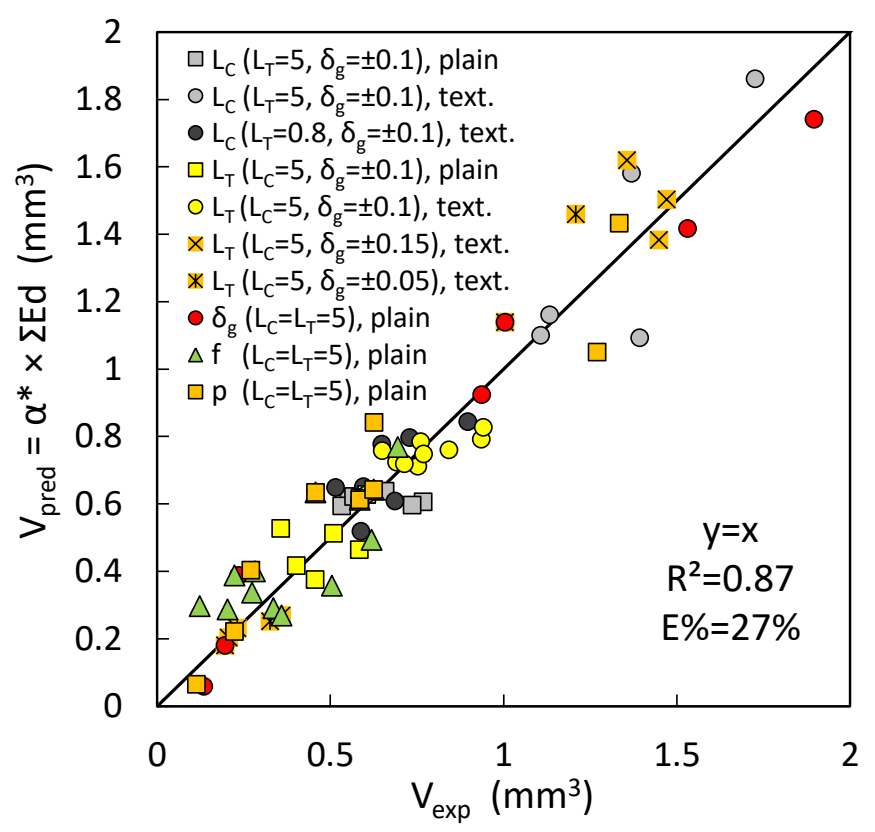

Fig. 22. Comparison between the experimental and predicted wear volumes (Eq. 28) by varying the contact size parameters $L_{C}(m m), L_{T}(m m)$, the sliding amplitude $\delta_{g}( \pm m m)$, the frequency and the contact pressure (except the mentioned conditions in the legend, the other loading parameters are kept constant at the reference condition: $\mathrm{N}_{\text {ref }}=20000$ cycles, $\mathrm{p}_{\mathrm{ref}}=100 \mathrm{MPa}, \mathrm{f}_{\mathrm{ref}}=1$ $\mathrm{Hz}, \delta_{g, r e}= \pm 0.1 \mathrm{~mm}, \mathrm{~L}_{\mathrm{C}, \mathrm{ref}}=\mathrm{L}_{\mathrm{T}, \mathrm{ref}}=5 \mathrm{~mm}$ where $\mathrm{f}$ and $\mathrm{p}$ experiments are extracted from [27]).

The basic weighted power-law formulation appears surprisingly well describing both COC and TBT interactions. However, more elaborated mathematical expressions could be considered in the future to better describe the very complex interactions involving both TBT and COC processes as well as the coupled interactions between them as discussed previously. For instance, the interface oxygenation process depends on the porosity of the debris bed, which itself depends on the thickness of this latter. Likewise, the oxygenation of the interface modifies the cohesive nature of the debris as shown in [40]: under ambient air the third body (TB) is powdery with iron oxides detected, whereas no oxidation is observed under pure argon and TB is highly compacted in the whole contact suggesting high cohesion between particles. Through a TB meshfree 
model, it was highlighted that different cohesion strengths induced distinct TB rheology and consequently different friction regimes [40]. The contact oxygenation also modifies the ejection process of the third body and therefore influences the TBT contribution. Thus, the complex coupling between COC and TBT suggests that a more elaborated formulation of the contact size effect needs to be considered in future developments.

However, one major interest of this power law formulation is the possibility to directly implement this expression in a previous power law expression describing the effect of contact pressure, sliding frequency and sliding amplitude [27].

\section{Conclusion}

This study inspects the contact size and the gross slip sliding amplitude effects on the fretting wear rate of $34 \mathrm{NiCrMo16}$ steel crossed flat-on-flat interface keeping constant the mean contact pressure, the sliding frequency and the fretting cycles. Combining both plain and macro-textured specimens, the experimental strategy consists in keeping constant the transverse contact size $\mathrm{L}_{\mathrm{T}}=5 \mathrm{~mm}$ while varying the longitudinal contact size $\mathrm{L}_{\mathrm{C}}$ along which the sliding amplitude is applied, then to maintain constant $\mathrm{L}_{\mathrm{C}}=5$ $\mathrm{mm}$ while varying $\mathrm{L}_{\mathrm{T}}$ in the same way. Using this strategy it was possible to investigate various collinear and transverse contact length scales keeping constant the total fretted area. The main points of the present paper are:

- Whatever the contact dimension the coefficient of friction appears constant and stabilized around 0.7 . This suggests that the friction coefficient is weakly affected by contact size effects at least for the studied flat-on-flat contact configuration. 
- Confirming former literature work, the experiments display an asymptotic decrease of the friction energy wear rate with the contact size. However, different evolutions have been observed by varying separately $\mathrm{L}_{\mathrm{C}}$ or $\mathrm{L}_{\mathrm{T}}$. The relative influence of the collinear length appears significantly higher than the transverse one. The plain friction energy wear approach comparing the wear volume versus the accumulated friction work is no more applicable.

- By comparing $\mathrm{L}_{\mathrm{C}}$ and $\mathrm{L}_{\mathrm{T}}$ wear rate responses, it is possible to decouple both contact oxygenation concept (i.e. COC: partition between adhesive and abrasive wear domains) and third body theory (i.e. TBT: debris ejection flow) regarding their respective contribution on the global wear rate.

- The COC contact contribution can be expressed as function of a representative $\mathrm{L}_{\mathrm{COC}}=\min \left(\mathrm{L}_{\mathrm{C}}, \mathrm{L}_{\mathrm{T}}\right)$ length scale according to the isotropic diffusion of di-oxygen molecules within the debris layer. Alternatively, the TBT process is better expressed using the collinear length scale according to the anisotropic behavior of the debris flow within the fretted interface (i.e. $\mathrm{L}_{\mathrm{TBT}}=\mathrm{L}_{\mathrm{C}}$ ).

- Combining $\mathrm{L}_{\text {Твт }}$ and sliding amplitude $\delta_{\mathrm{g}}$ experiments, a master curve is obtained describing the evolution of the friction energy wear rate as a function of the $\mathrm{N}_{\text {TBT }}=$ $\mathrm{L}_{\mathrm{TBT}} / \delta_{\mathrm{g}}$ ratio. This suggests a synergic interaction between the collinear length scale and the fretting sliding amplitude regarding the debris ejection process.

- A power-law approach is introduced to model the contact size effect on the fretting wear rate fluctuation where the TBT wear rate contribution is expressed as a function of the $\mathrm{L}_{\mathrm{TBT}} / \delta_{\mathrm{g}}$ ratio weighted by a COC contribution expressed as a function of the $\mathrm{L}_{\mathrm{COC}}$ 
contact length scale. The very good correlation with experiments confirms the stability of the proposal.

- This contact size effect formulation is combined with a previous weighted friction energy wear approach [27] taking into account the effect of the sliding frequency and the contact pressure. Despite the simplicity of the derived extended friction energy wear rate expression, very good correlations with numerous experiments support the stability of the approach.

\section{Acknowledgment}

The authors gratefully acknowledge the French National Research Agency (ANR, France) and the Ecole Centrale de Lyon (ECL, France) for financially supporting this research project (ANR-16-CE08-0016). Gratitude also goes to Jean-Michel Vernet and Julie Laporte for their appreciated help.

\section{References}

[1] D. Hoeppner, Mechanisms of fretting fatigue and their impact on test methods development., ASTM STP. 1159 (1992) $23-32$. https://doi.org/10.1520/STP25809S.

[2] O. Vingsbo, S. Soderberg, On fretting maps, Wear. 126 (1988) 131-147. doi:10.1016/0043-1648(88)90134-2.

[3] R.B. Waterhouse, D.E. Taylor, Fretting debris and the delamination theory of wear, Wear. 29 (1974) 337-344. doi:10.1016/00431648(74)90019-2.

[4] D.A. Hills, Mechanics of fretting fatigue, Wear. 175 (1994) 107-113. doi:10.1016/0043-1648(94)90173-2.

[5] S. Fouvry, P. Kapsa, L. Vincent, Quantification of fretting damage, Wear. 200 (1996) 186-205. doi:10.1016/S0043-1648(96)07306-1.

[6] A.M. Kirk, P.H. Shipway, W. Sun, C.J. Bennett, Debris development in fretting contacts - Debris particles and debris beds, Tribol. Int. (2019) 1-9. doi:10.1016/j.triboint.2019.01.051.

[7] Z. bing Cai, M. hao Zhu, Z. rong Zhou, An experimental study torsional fretting behaviors of LZ50 steel, Tribol. Int. 43 (2010) $361-369$. doi:10.1016/j.triboint.2009.06.016.

[8] M.R. Hirsch, R.W. Neu, Temperature-dependent fretting damage of high strength stainless steel sheets, Wear. $346-347$ (2016) 6-14. doi:10.1016/j.wear.2015.10.007.

[9] T. Zhu, P.H. Shipway, W. Sun, The dependence of wear rate on wear scar size in fretting; the role of debris (third body) expulsion from the contact, Wear. 440-441 (2019) 203081. doi:10.1016/j.wear.2019.203081.

[10] T. Zhu, P.H. Shipway, Contact size and debris ejection in fretting: The inappropriate use of Archard-type analysis of wear data and the development of alternative wear equations for commonly employed non-conforming specimen pair geometries, Wear. 474-475 (2021) 203710. doi:10.1016/j.wear.2021.203710.

[11] A. Dreano, S. Fouvry, G. Guillonneau, Understanding and formalization of the fretting-wear behavior of a cobalt-based alloy at high temperature, Wear. 452-453 (2020) 203297. doi:10.1016/j.wear.2020.203297.

[12] P.H. Shipway, Time-dependence and exposure-dependence of material removal rates in fretting, Wear. (2021) 203826. doi:10.1016/j.wear.2021.203826.

[13] J.F. Archard, Contact and rubbing of flat surfaces, J. Appl. Phys. 24 (1953) 981-988. doi:10.1063/1.1721448.

[14] H. Mohrbacher, B. Blanpain, J.P. Celis, J.R. Roos, L. Stals, M. Van Stappen, Oxidational wear of TiN coatings on tool steel and nitrided tool steel in unlubricated fretting, Wear. 188 (1995) 130-137. doi:10.1016/0043-1648(95)06637-3.

[15] S. Fouvry, P. Kapsa, H. Zahouani, L. Vincent, Wear analysis in fretting of hard coatings through a dissipated energy concept, Wear. 1648 (1997) 393-403.

[16] T. Liskiewicz, S. Fouvry, Development of a friction energy capacity approach to predict the surface coating endurance under complex oscillating sliding conditions, Tribol. Int. 38 (2005) 69-79. doi:10.1016/j.triboint.2004.06.002.

[17] Y. Berthier, M. Godet, M. Brendle, Velocity accommodation in friction, Tribol. Trans. 32 (1989) 490-496. doi:10.1080/10402008908981917.

[18] N. Fillot, I. lordanoff, Y. Berthier, Wear modeling and the third body concept, Wear. 262 (2007) 949-957. doi:10.1016/j.wear.2006.10.011.

[19] S. Descartes, Y. Berthier, Rheology and flows of solid third bodies: Background and application to an MoS1.6coating, Wear. 252 (2002) 546-556. doi:10.1016/S0043-1648(02)00008-X.

[20] S. Fouvry, C. Paulin, S. Deyber, Impact of contact size and complex gross-partial slip conditions on Ti-6Al-4V/Ti-6Al-4V fretting wear, Tribol. 
Int. 42 (2009) 461-474. doi:10.1016/j.triboint.2008.08.005.

[21] R. Merhej, S. Fouvry, Contact size effect on fretting wear behaviour: application to an AISI 52100/AISI 52100 interface, Lubr. Sci. 24 (2012) 273-290. doi:10.1002/ls.

[22] S. Fouvry, R. Merhej, Introduction of a power law formulation to quantify the contact size effects on friction and wear responses of dry oscillating sliding contacts: Application to a chromium steel interface, Wear. 301 (2013) 34-46. doi:10.1016/j.wear.2013.01.072.

[23] J. Hintikka, A. Lehtovaara, A. Mäntylä, Third Particle Ejection Effects on Wear with Quenched and Tempered Steel Fretting Contact, Tribol. Trans. 60 (2017) 70-78. doi:10.1080/10402004.2016.1146813.

[24] S. Fouvry, P. Arnaud, A. Mignot, P. Neubauer, Contact size, frequency and cyclic normal force effects on Ti-6Al-4V fretting wear processes: An approach combining friction power and contact oxygenation, Tribol. Int. 113 (2017) 460-473. doi:10.1016/j.triboint.2016.12.049.

[25] A.R. Warmuth, S.R. Pearson, P.H. Shipway, W. Sun, The effect of contact geometry on fretting wear rates and mechanisms for a high strengthsteel, Wear. 301 (2013) 491-500. doi:10.1016/j.wear.2013.01.018.

[26] P. Arnaud, S. Baydoun, S. Fouvry, Modeling adhesive and abrasive wear phenomena in fretting interfaces: A multiphysics approach coupling friction energy, third body and contact oxygenation concepts, Tribol. Int. 161 (2021) 107077. doi:10.1016/j.triboint.2021.107077.

[27] S. Baydoun, S. Fouvry, S. Descartes, P. Arnaud, Fretting wear rate evolution of a flat-on-flat low alloyed steel contact: A weighted friction energy formulation, Wear. 426-427 (2019) 676-693. doi:10.1016/j.wear.2018.12.022.

[28] M. Varenberg, G. Halperin, I. Etsion, Different aspects of the role of wear debris in fretting wear, Wear. 252 (2002) $902-910$. doi:10.1016/S0043-1648(02)00044-3.

[29] C. Mary, S. Fouvry, J.M. Martin, B. Bonnet, Pressure and temperature effects on Fretting Wear damage of a Cu-Ni-In plasma coating versus Ti17 titanium alloy contact, Wear. 272 (2011) 18-37. doi:10.1016/j.wear.2011.06.008.

[30] A. Iwabuchi, The role of oxide particles in the fretting wear of mild steel, Wear. 151 (1991) 301-311. doi:10.1016/0043-1648(91)90257-U.

[31] A. Iwabuchi, K. Hori, H. Kubosawa, The effect of oxide particles supplied at the interface before sliding on the severe-mild wear transition, Wear. 128 (1988) 123-137. doi:10.1016/0043-1648(88)90179-2.

[32] S. Baydoun, P. Arnaud, S. Fouvry, Modelling adhesive wear extension in fretting interfaces: An advection-dispersion-reaction contact oxygenation approach, Tribol. Int. 151 (2020) 106490. doi:10.1016/j.triboint.2020.106490.

[33] P. Arnaud, S. Fouvry, A dynamical FEA fretting wear modeling taking into account the evolution of debris layer, Wear. 412-413 (2018) 92108. doi:10.1016/j.wear.2018.07.018.

[34] F.J. Quinn, Role of oxidation in the mild wear of steel, Br. J. Appl. Phys. 13 (1962) 33-37.

[35] A. Dréano, S. Fouvry, G. Guillonneau, A tribo-oxidation abrasive wear model to quantify the wear rate of a cobalt-based alloy subjected to fretting in low-to-medium temperature conditions, Tribol. Int. 125 (2018) 128-140. doi:10.1016/j.triboint.2018.04.032.

[36] P.H. Shipway, A.M. Kirk, C.J. Bennett, T. Zhu, Understanding and modelling wear rates and mechanisms in fretting via the concept of ratedetermining processes - Contact oxygenation, debris formation and debris ejection, Wear. 486-487 (2021) 204066. doi:10.1016/j.wear.2021.204066.

[37] K.L. Johnson, Contact mechanics, Cambridge University Press, 1985

[38] S. Fouvry, P. Kapsa, L. Vincent, Elastic-plastic shakedown analysis of fretting wear, Wear. 247 (2001) 41-54. doi:10.1016/S00431648(00)00508-1.

[39] S. Baydoun, Investigation of fretting wear of a flat-on-flat 34NiCrMo16 interface: Application and modelling of the contact oxygenation concept, PhD Thesis - Ecole Centrale de Lyon, 2020. University of Lyon, 2020LYSEC (https://bibli.ec-lyon.fr/exldoc/TH_T2726_sbaydoun.pdf).

[40] Y. Zhang, G. Mollon, S. Descartes, Significance of third body rheology in friction at a dry sliding interface observed by a multibody meshfree model: Influence of cohesion between particles, Tribol. Int. 145 (2020) 106188. doi:10.1016/j.triboint.2020.106188. 